\title{
A New Look at Stratospheric Sudden Warmings. Part I: Climatology and Modeling Benchmarks
}

\author{
ANDREW J. CHARLTON* \\ Department of Applied Physics and Applied Mathematics, Columbia University, New York, New York \\ LoRenZo M. Polvani \\ Department of Applied Physics and Applied Mathematics, and Department of Earth and Environmental Sciences, \\ Columbia University, New York, New York
}

(Manuscript received 13 October 2005, in final form 28 March 2006)

\begin{abstract}
Stratospheric sudden warmings are the clearest and strongest manifestation of dynamical coupling in the stratosphere-troposphere system. While many sudden warmings have been individually documented in the literature, this study aims at constructing a comprehensive climatology: all major midwinter warming events are identified and classified, in both the NCEP-NCAR and 40-yr ECMWF Re-Analysis (ERA-40) datasets. To accomplish this a new, objective identification algorithm is developed. This algorithm identifies sudden warmings based on the zonal mean zonal wind at $60^{\circ} \mathrm{N}$ and $10 \mathrm{hPa}$, and classifies them into events that do and do not split the stratospheric polar vortex.

Major midwinter stratospheric sudden warmings are found to occur with a frequency of approximately six events per decade, and $46 \%$ of warming events lead to a splitting of the stratospheric polar vortex. The dynamics of vortex splitting events is contrasted to that of events where the vortex is merely displaced off the pole. In the stratosphere, the two types of events are found to be dynamically distinct: vortex splitting events occur after a clear preconditioning of the polar vortex, and their influence on middle-stratospheric temperatures lasts for up to 20 days longer than vortex displacement events. In contrast, the influence of sudden warmings on the tropospheric state is found to be largely insensitive to the event type.

Finally, a table of dynamical benchmarks for major stratospheric sudden warming events is compiled. These benchmarks are used in a companion study to evaluate current numerical model simulations of the stratosphere.
\end{abstract}

\section{Introduction}

Over the last decade our understanding of the relationship between the stratosphere and troposphere has been radically altered. While the influence of tropospheric waves on the stratospheric circulation has been recognized since Matsuno's early models of stratospheric sudden warmings (SSWs; Matsuno 1971), the influence of stratospheric conditions on the tropo-

* Current affiliation: Department of Meteorology, University of Reading, Reading, United Kingdom.

Corresponding author address: Andrew J. Charlton, Department of Meteorology, University of Reading, Reading, Berkshire, RG6 6BB, United Kingdom.

E-mail: a.j.charlton@reading.ac.uk spheric flow has only recently become widely accepted. Both observational studies (Baldwin and Dunkerton 2001; Thompson et al. 2002; Thompson and Solomon 2002) and modeling studies (Shindell et al. 1999; Sexton 2001; Polvani and Kushner 2002; Gillett and Thompson 2003; Norton 2003; Charlton et al. 2004) have provided strong evidence that the stratospheric state is able to influence the tropospheric circulation. As a consequence, the stratosphere is coming to be seen as more than a passive absorber of tropospheric planetary waves, and the emerging paradigm is one of a two-way coupled system.

SSW events are the clearest and strongest manifestation of the coupling of the stratosphere-troposphere system. Recent work has shown that the influence of SSWs on the tropospheric flow can last for many weeks (Baldwin and Dunkerton 2001; Polvani and Waugh 2004). It is therefore important to correctly represent 
stratospheric dynamics, and its coupling to the troposphere in numerical models of the climate system. A useful analogy might be drawn at this point with the atmosphere-ocean system: in the same way as understanding and successfully modeling the El Niño-Southern Oscillation phenomenon is of primary importance for the atmosphere-ocean system, understanding and successfully modeling stratospheric sudden warming events is of primary importance for the stratospheretroposphere system.

Given the prominent role of SSW events, it is somewhat surprising that relatively few attempts have been made to establish a comprehensive climatology of SSWs; this is the aim of the current work which, encompasses two related papers. In this first paper we construct a climatology of major, midwinter, stratospheric sudden warmings, together with a set of dynamical benchmarks for their simulation in numerical models. In the second paper we examine a number of stratosphere resolving GCMs and assess their ability to simulate the observed characteristics of SSWs.

Since the discovery of SSWs by Scherhag (1952), many studies have examined the dynamics of individual major warming events. Only a few studies, however, have attempted to establish a climatology of SSWs, including those by Labitzke (1977) and Manney et al. (2005). This study builds on those earlier works and is novel and distinctive in three important respects. First, we provide full dating information for SSWs, including the day of occurrence, and tabulate all events from the late 1950s to the present in a single table. Second, our climatology is established from two widely used reanalysis datasets, which to our knowledge have not been examined for SSW activity before. Third, we use a new analysis technique that, for the first time, classifies the SSWs into vortex displacement and splitting events.

This study is also closely related to that of Limpasuvan et al. (2004, hereafter LIM04). However, while the latter used the 50-hPa annular mode to define SSWs and considered only the National Centers for Environmental Prediction-National Center for Atmospheric Research (NCEP-NCAR) reanalysis dataset, we here adhere to the more widely used World Meteorological Organization (WMO) definition of SSWs (easterly winds at $10 \mathrm{hPa}$ and $60^{\circ} \mathrm{N}$ ), and we examine both the NCEP-NCAR and the 40-yr European Centre for Medium-Range Weather Forecasts (ECMWF) ReAnalysis (ERA-40) datasets.

In this study we also distinguish between different types of SSWs, based on the synoptic structure in the middle stratosphere. Following O'Neill (2003), one type, a vortex displacement, is characterized by a clear shift of the polar vortex off the pole, and its subsequent distortion into a "comma shape" during the extrusion of a vortex filament; an example is given in Fig. 1a. The other type, a vortex split, is easily recognizable in that the polar vortex breaks up into two pieces of comparable size (Fig. 1b). While these two types of SSWs are often associated with large amplitudes of longitudinal wavenumbers 1 and 2, respectively, a simple Fourier decomposition is not sufficient to identify them (Waugh 1997, their appendix): a more sophisticated algorithm is needed.

In section 2 this new algorithm is described in detail. In sections 3 to 6 , using this new tool, we then attempt to answer the following key questions:

- How often do SSWs occur, and what is the ratio of vortex displacements to vortex splits?

- What is the temporal distribution of SSWs?

- Are vortex displacements and vortex splits dynamically different? If so how?

- Do vortex displacements and vortex splits differ in their impacts on the tropospheric flow?

In section 7, we construct a set of modeling benchmarks for SSWs, and we conclude with a brief summary of our findings in section 8 .

\section{Sudden warming identification and classification algorithm}

In this section we describe the key tool that we have developed for the present study: an algorithm for automatically identifying and classifying SSWs. This tool is needed because we intend to examine SSWs in many different datasets (both reanalyses and model outputs) and, for validation purposes, it is essential that such an examination be done objectively. Also, the task of identifying and classifying SSWs is, de facto, humanly impossible as many, large datasets need to analyzed.

In view of this, special care is needed in designing the detection/classification algorithm. In particular the algorithm should use only those variables that are typically archived on at least daily time scales by general circulation model (GCM) simulations and should not involve diagnostics that require fine vertical resolution to be calculated offline. In addition, the algorithm has been designed to minimize the number of variables that need to be derived from the direct GCM output, in order to avoid introducing unnecessary interpolation and differentiation errors, as well as to simplify the analysis.

The algorithm consists of two parts: first SSWs are identified, and second they are classified as vortex displacement or vortex splitting events. These two steps 

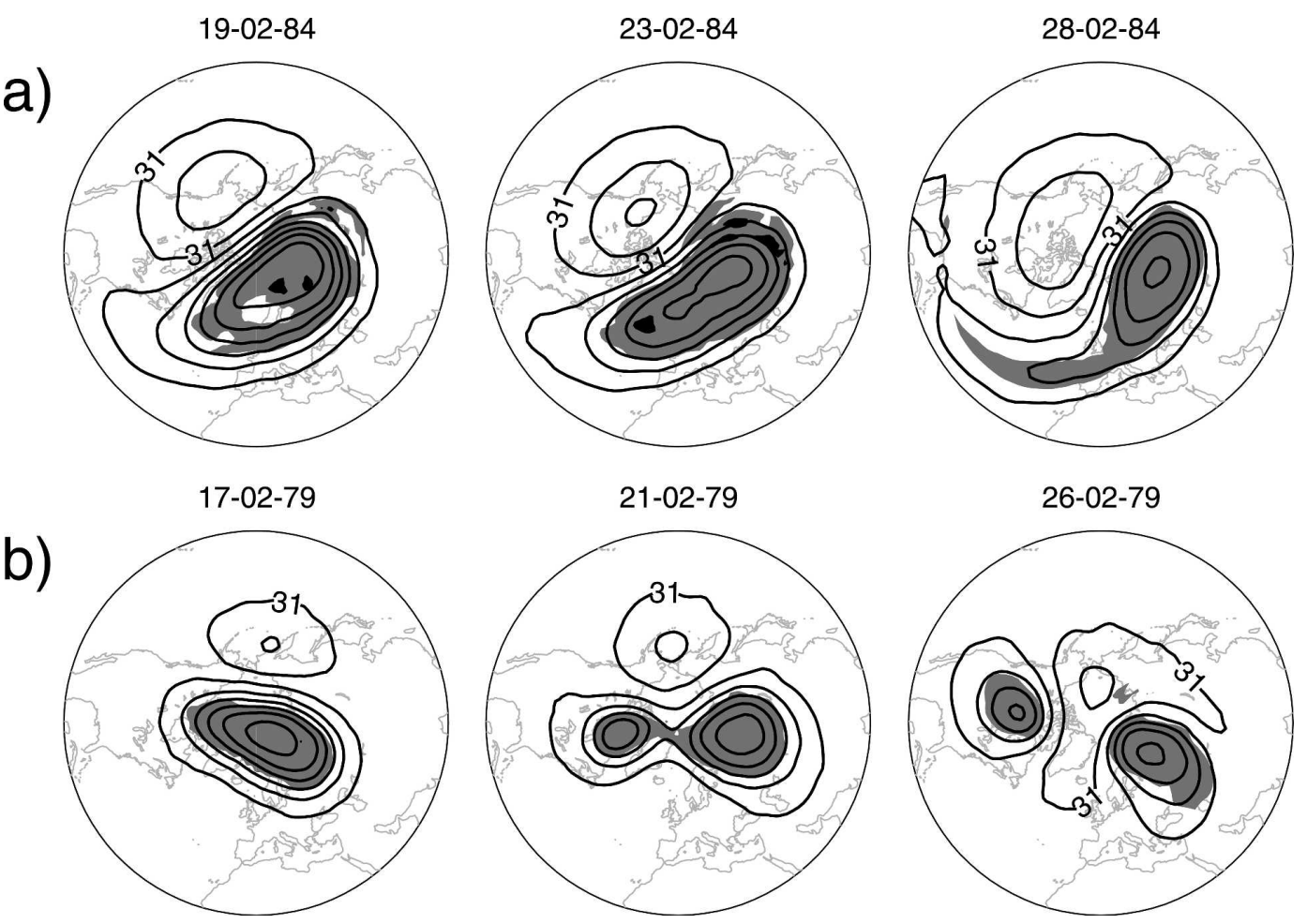

FIG. 1. Polar stereographic plot of geopotential height (contours) on the 10-hPa pressure surface. Contour interval is $0.4 \mathrm{~km}$, and shading shows potential vorticity greater than $4.0 \times 10^{-6} \mathrm{~K} \mathrm{~kg}^{-1} \mathrm{~m}^{2} \mathrm{~s}^{-1}$. (a) A vortex displacement type warming that occurred in February 1984. (b) A vortex splitting type warming that occurred in February 1979.

are described, separately, in the following subsections. The discussion is somewhat technical in nature and is included here for the sake of completeness and reproducibility. Some readers may wish to skip directly to the next section, where we present the results obtained by applying the algorithm to the NCEP-NCAR and ERA40 datasets.

\section{a. Identifying sudden warming events}

We have decided to follow the WMO definition (Andrews et al. 1985, p. 259), also used for the widely known STRATALERT messages (Labitzke and Naujokat 2000) in order to detect the occurrence of the SSWs: a major midwinter warming occurs when the zonal mean zonal winds at $60^{\circ} \mathrm{N}$ and $10 \mathrm{hPa}$ become easterly during winter, defined here as NovemberMarch (NDJFM). Note that our definition differs from that used by Labitzke and others in several studies in that we do not attempt to exclude Canadian warmings from our definition and that we also include events in March that would be rejected by some authors. The first day on which the daily mean zonal mean zonal wind at $60^{\circ} \mathrm{N}$ and $10 \mathrm{hPa}$ is easterly is defined as the central date of the warming. Note that this definition differs from that of LIM04, who identify warmings by reduction in strength of a stratospheric zonal index, based on the first empirical orthogonal function of 50$\mathrm{hPa}$ geopotential height.

We note that the WMO definition, in addition to the reversal of the winds at $60^{\circ} \mathrm{N}$ and $10 \mathrm{hPa}$, requires that the 10-hPa zonal mean temperature gradient between $60^{\circ}$ and $90^{\circ} \mathrm{N}$ be positive (Kruger et al. 2005) for an event to be designated as a major midwinter warming. Including this additional constraint makes only a small difference to the number of SSWs identified (only three events in the NCEP-NCAR dataset and one in the ERA-40 dataset do not meet this criterion). Thus, to avoid unnecessary complexity, we have not included the temperature gradient criterion ${ }^{1}$ in our algorithm.

Once a warming is identified, no day within 20 days of the central date can be defined as an SSW. The length of the interval is chosen to approximately equal two radiative time scales at $10 \mathrm{hPa}$ (Newman and

\footnotetext{
${ }^{1}$ There also appears to be some ambiguity as to the exact specification of the temperature gradient criterion for defining major stratospheric warmings. Contrast, for instance, Limpasuvan et al. (2004, p. 2587) with Kruger et al. (2005, p. 603).
} 
Rosenfield 1997). This condition prevents the algorithm from counting the same SSW twice, as the zonal mean zonal winds might fluctuate between westerly and easterly values following the onset of the warming.

Finally, it is important to highlight that only midwinter warmings are considered in this study. To ensure this, cases where the zonal mean zonal winds become easterly but do not return to westerly for at least 10 consecutive days before 30 April are assumed to be final warmings, and as such are discarded. This criterion ensures that following SSWs, a coherent stratospheric vortex is reestablished.

\section{b. Classifying sudden warming events}

Once an SSW has been identified, the second part of the algorithm classifies it as a vortex displacement or a vortex split. This involves identifying the number and relative sizes of cyclonic vortices during the evolution of the warming. Ideally, one would want to work with Ertel potential vorticity (EPV) on an isentropic surface, as in Waugh and Randel (1999), to identify stratospheric vortices. In practice, however, EPV is not frequently archived in model output datasets.

We have therefore decided to work with $\zeta_{p}$, the absolute vorticity on pressure surfaces, as a substitute for EPV. This presents several advantages: $\zeta_{p}$ is readily computed from the velocity field, and this can easily ${ }^{2}$ be done with spectral accuracy. Furthermore, no vertical interpolation is needed, as most model levels in the middle atmosphere are in fact pressure levels. As Baldwin and Holton (1988) have shown, $\zeta_{p}$ is well suited for looking at the outer contours of the polar vortex and defining the vortex edge.

Identifying vortices in the $\zeta_{p}$ field involves determining the value of $\zeta_{p}$ at each vortex edge. We tested a variant of the Nash et al. (1996) algorithm, using $\zeta_{p}$ instead of EPV, but found it to be unreliable during SSWs when two or more vortices were present. In these SSWs the equivalent latitude averaging procedure had a tendency to mix the EPV gradient structure of the two vortices together and make it difficult to identify the vortex edge. To avoid such averaging, we have adopted an algorithm from early computer vision studies (Castleman 1996). Specifically, the edges of each vortex are identified as the location of the maximum horizontal gradient in $\zeta_{p}$, and these are computed by finding locations of the zeros in the Laplacian of $\zeta_{p}$. Our algorithm, therefore, follows Nash et al. (1996) in that it identifies the vortex edges as the locations of maximum

\footnotetext{
${ }^{2}$ For instance, absolute vorticity could be calculated with the SPHEREPACK routines (Adams and Swarztrauber 1999).
}

vorticity gradients, but it accomplishes this with no horizontal averaging.

In detail, our algorithm proceeds as follows: for each of the days between 5 days before the central date and 10 days after the central date one executes the steps below. If at least one day meets all of the criteria in the loop, the SSW is classified as a vortex split. Otherwise the SSW is classified as a vortex displacement.

1) Compute $\zeta_{p}$ at $10 \mathrm{hPa}$ and smooth it. If not directly available, $\zeta_{p}$ is easily obtained from the horizontal wind components. To reduce noise, filter $\zeta_{p}$ with a triangular truncation of the spherical harmonic coefficients and retain up to total wavenumber $n_{T}$.

2) Compute the Laplacian of $\zeta_{p}$. The field $\nabla^{2} \zeta_{p}$ is needed to find the value of $\zeta_{p}$ that defines the edge of the vortex (Castleman 1996).

3) Construct $n_{C}$ contours, $C\left(\zeta_{p}\right)$, which enclose the maximum $^{3}$ of $\zeta_{p}$. The algorithm aims to find the vortices using the vortex edge defined from the biggest vortex.

4) Compute the mean absolute value of $\nabla^{2} \zeta_{p}$ on $C\left(\zeta_{p}\right)$. For a very smooth field, the Laplacian itself would identify the closed region corresponding to the biggest vortex. This extra smoothing is required because the $\zeta_{p}$ field is noisy.

5) Define the vortex edge $Z_{E}$. This is the value of $\zeta_{p}$ on the contour in $C\left(\zeta_{p}\right)$ with minimum mean absolute value of $\nabla^{2} \zeta_{p}$, and closest to the maximum $\zeta_{p}$.

6) Compute the number of closed contours with value $Z_{E}$ in the $\zeta_{p}$ field. If two or more such contours of $Z_{E}$ exist, proceed to the next step. Otherwise skip it.

7) Calculate the circulation around the two largest contours of $Z_{E}$. This is done using Stokes' theorem, and the aim is to compare the strength of the two largest vortices. If the ratio of their circulations is greater than a given threshold, $R_{\zeta}$, classify this SSW as a vortex split.

The algorithm includes a number of tunable parameters, which were chosen to give the best possible performance. The values used to produce the results discussed in this and the following paper are as follows: $n_{T}=11, n_{C}=11$, and $R_{\zeta}=0.5$. These values were empirically determined, to give the best agreement between the output of the algorithm (in terms of detected SSWs and their type) and a subjective analysis of the

\footnotetext{
${ }^{3}$ In our algorithm, contours that enclose the maximum absolute vorticity are found by considering the 8-point adjacency of grid points to the maximum absolute vorticity, making binary images of these grid points and then contouring the binary images. Other methods, such as winding number contour based methods, could be used.
} 
TABLE 1. SSWs identified in NCEP-NCAR and ERA-40 datasets. D indicates a vortex displacement and S indicates a vortex split. $\Delta T_{10}$ shows the mean area-weighted polar cap temperature anomaly at $10 \mathrm{hPa} \pm 5$ days from the central date. Warmings that are also ESEs [in the sense of Baldwin and Dunkerton (2001), see text] are in bold.

\begin{tabular}{|c|c|c|c|c|c|c|c|}
\hline No. & $\begin{array}{l}\text { Central date, } \\
\text { NCEP-NCAR }\end{array}$ & $\begin{array}{l}\text { Central date, } \\
\text { ERA-40 }\end{array}$ & $\begin{array}{c}\text { Type } \\
\text { subject }\end{array}$ & $\begin{array}{c}\text { Type } \\
\text { NCEP-NCAR }\end{array}$ & $\begin{array}{c}\text { Type } \\
\text { ERA-40 }\end{array}$ & $\begin{array}{l}\Delta T_{10} \\
\left({ }^{\circ} \mathrm{K}\right)\end{array}$ & References \\
\hline 1 & 30 Jan 1958 & 31 Jan 1958 & $\mathrm{~S}$ & $\mathrm{~S}$ & $\mathrm{~S}$ & 7.8 & Teweles and Finger (1958) \\
\hline 2 & 30 Nov 1958 & & $\mathrm{D}$ & $\mathrm{D}$ & & 7.7 & Hare (1960) \\
\hline 3 & 16 Jan 1960 & 15 Jan1960 & $\mathrm{D}$ & $\mathrm{D}$ & $\mathrm{D}$ & 5.9 & \\
\hline 4 & & 28 Jan 1963 & $\mathrm{~S}$ & & $\mathrm{~S}$ & 10.5 & Finger and Teweles (1964) \\
\hline 5 & 23 Mar 1965 & & S & S & & 4.4 & \\
\hline 6 & 8 Dec 1965 & 16 Dec 1965 & $\mathrm{D}$ & $\mathrm{D}$ & $\mathrm{D}$ & 6.7 & Johnson et al. (1969) \\
\hline 7 & 24 Feb1966 & 23 Feb 1966 & S & S & S & 3.1 & Quiroz (1969) \\
\hline 8 & 8 Jan 1968 & 7 Jan 1968 & S & S & S & 12.0 & Johnson et al. (1969) \\
\hline 9 & 27 Nov 1968 & 28 Nov 1968 & $\mathrm{D}$ & S & $\mathrm{D}$ & 5.3 & \\
\hline 10 & 13 Mar 1969 & 13 Mar 1969 & $\mathrm{D}$ & $\mathrm{D}$ & $\mathrm{D}$ & 4.3 & \\
\hline 11 & 2 Jan 1970 & 1 Jan 1970 & $\mathrm{D}$ & $\mathrm{D}$ & $\mathrm{D}$ & 6.8 & Quiroz (1975) \\
\hline 12 & 17 Jan 1971 & 18 Jan 1971 & $\mathrm{~S}$ & $\mathrm{~S}$ & $\mathrm{~S}$ & 9.6 & Quiroz (1975) \\
\hline 13 & 20 Mar 1971 & 19 Mar 1971 & $\mathrm{D}$ & $\mathrm{D}$ & S & -2.9 & \\
\hline 14 & 2 Feb 1973 & 31 Jan 1973 & S & S & S & 6.6 & Quiroz (1975) \\
\hline 15 & & 9 Jan 1977 & S & & S & 9.1 & O'Neill and Youngblut (1982) \\
\hline 16 & 22 Feb 1979 & 22 Feb 1979 & S & S & S & 3.7 & Palmer (1981) \\
\hline 17 & 29 Feb 1980 & 29 Feb 1980 & $\mathrm{D}$ & $\mathrm{D}$ & $\mathrm{D}$ & 11.5 & Baldwin and Holton (1988) \\
\hline 18 & & 4 Mar 1981 & $\mathrm{D}$ & & $\mathrm{D}$ & -2.9 & \\
\hline 19 & 4 Dec 1981 & 4 Dec 1981 & $\mathrm{D}$ & $\mathrm{D}$ & $\mathrm{D}$ & 0.1 & \\
\hline 20 & $24 \mathrm{Feb} 1984$ & 24 Feb 1984 & $\mathrm{D}$ & $\mathrm{D}$ & $\mathrm{D}$ & 11.1 & \\
\hline 21 & 2 Jan 1985 & 1 Jan 1985 & S & S & S & 13.0 & Randel and Boville (1987) \\
\hline 22 & 23 Jan 1987 & 23 Jan 1987 & $\mathrm{D}$ & $\mathrm{D}$ & $\mathrm{D}$ & 10.2 & Manney et al. (2005) \\
\hline 23 & 8 Dec 1987 & 7 Dec 1987 & $\mathrm{~S}$ & $\mathrm{~S}$ & $\mathrm{~S}$ & 14.1 & Baldwin and Dunkerton (1989) \\
\hline 24 & 14 Mar 1988 & 14 Mar 1988 & S & $\mathrm{D}$ & S & 11.7 & \\
\hline 25 & 22 Feb 1989 & 21 Feb 1989 & S & S & S & 12.8 & Kruger et al. (2005) \\
\hline 26 & 15 Dec 1998 & 15 Dec 1998 & $\mathrm{D}$ & $\mathrm{D}$ & $\mathrm{D}$ & 12.7 & Manney et al. (1999) \\
\hline 27 & 25 Feb 1999 & 26 Feb 1999 & S & S & S & 11.0 & Charlton et al. (2004) \\
\hline 28 & 20 Mar 2000 & 20 Mar 2000 & $\mathrm{D}$ & $\mathrm{D}$ & $\mathrm{D}$ & 5.3 & \\
\hline 29 & 11 Feb 2001 & 11 Feb 2001 & S & $\mathrm{D}$ & $\mathrm{D}$ & 6.3 & Jacobi et al. (2003) \\
\hline 30 & 2 Jan 2002 & 30 Dec 2001 & $\mathrm{D}$ & $\mathrm{D}$ & $\mathrm{D}$ & 12.9 & Naujokat et al. (2002) \\
\hline 31 & & $17 \mathrm{Feb} 2002$ & $\mathrm{D}$ & & $\mathrm{D}$ & 5.6 & \\
\hline
\end{tabular}

fields on the 10-hPa pressure surface, using both the NCEP-NCAR and ERA-40 datasets, as described in the next section.

\section{Stratospheric sudden warmings and their classification: 1958-2002}

We start by presenting, in Table 1 , the results of our new algorithm when applied to two widely available reanalysis datasets: the first is from the NCEP-NCAR reanalysis project (Kistler et al. 2001), and the second is from the ERA-40 reanalysis project (Kallberg et al. 2004). For simplicity and ease of comparison, we here consider only the time period over which data are available in both datasets, that is, from 1 September 1957 to 31 August 2002, a total of 45 winter seasons (November-March) in the Northern Hemisphere. During that period, about $30 \mathrm{SSWs}$ were detected by our algorithm. Some of these SSWs have been analyzed individually in earlier studies; however, such a summary table $\mathrm{e}^{4}$ has not, to the best of our knowledge, appeared in the literature to date. In the last column of Table 1, we give references for many of the SSWs in the literature, if available; some SSWs, notably those in February 1979, have been extensively studied (see, e.g., Andrews et al. 1985), and only an example reference is included. We wish to emphasize that none of the SSWs in this table are final warmings, as our algorithm was specifically designed to exclude those.

In the second and third column of Table 1, we report the central date for all SSWs identified by our algorithm in either dataset. When SSWs are identified in both datasets and obviously refer to the same event, they are listed on the same line, even though the central

\footnotetext{
${ }^{4}$ We note that the yearly published Arctic winter reports in the "Beilage zur Berliner Wetterkarte" mention many of the events described here. Short summaries can be found in Labitzke (1977) and Naujokat and Labitzke (1993).
} 
TABLE 2. Summary statistics for the different datasets, and the combined values. The quantity $\Delta T$ is the mean over the SSWs of the values in row 7 in Table 1 (the numbers in parentheses give the standard deviation over the ensemble).

\begin{tabular}{lccccccc}
\hline \hline \multicolumn{1}{c}{ Dataset } & $\begin{array}{c}\text { Total } \\
\text { SSWs }\end{array}$ & $\begin{array}{c}\text { Displacement } \\
\text { SSWs }\end{array}$ & $\begin{array}{c}\text { Splitting } \\
\text { SSWs }\end{array}$ & SSWs/winter & Ratio & $\begin{array}{c}\Delta T\left({ }^{\circ} \mathrm{K}\right) \\
\text { displacements }\end{array}$ & $\begin{array}{c}\Delta T\left({ }^{\circ} \mathrm{K}\right) \\
\text { splits }\end{array}$ \\
\hline NCEP-NCAR & 27 & 15 & 12 & 0.60 & 1.25 & $6.8(4.6)$ & $8.1(3.7)$ \\
ERA-40 & 29 & 15 & 14 & 0.64 & 1.10 & $7.4(4.8)$ & $9.1(4.9)$ \\
Combined & 28 & 15 & 13 & 0.62 & 1.18 & $7.1(4.7)$ & $8.6(4.3)$ \\
\hline
\end{tabular}

date might be slightly different. When SSWs are found in one but not the other dataset, the entries for the dataset with no warming are left blank.

In columns 4-6, the SSW type is reported: "D" denotes a vortex displacement, and "S" a vortex split. The fourth column shows the classification that results from a subjective analysis of the SSWs. Note that the automatic classification resulting from our algorithm compares well with the subjective analysis: only 3 of the 27 SSWs in the NCEP-NCAR dataset and 2 of the 29 SSWs in the ERA-40 dataset are classified differently ${ }^{5}$ by the algorithm and the subjective analysis.

Also worth commenting on is the relationship between SSWs in Table 1, and the so-called "extreme stratospheric events" (ESEs; Baldwin and Dunkerton 2001), which have recently received much attention. ESEs are characterized by extreme values of the Northern Annular Mode (NAM) index at $10 \mathrm{hPa}$. SSWs that are identified as ESEs are listed in bold type in Table 1: 17 of the 18 ESEs are in fact major, midwinter stratospheric sudden warmings (the 18th ESE, on 2 March 1995 , occurs during a period of weak stratospheric winds that just fail to meet the major warming criterion). However, only $62 \%$ of the SSWs in the NCEPNCAR dataset and $58 \%$ of the SSWs in the ERA-40 dataset are also ESEs. Furthermore, there is no apparent relationship between the type of warming event and the NAM index: 10 of the ESEs are vortex splits, while 7 are vortex displacements.

We are now ready to answer the first question posed in the introduction, as summarized in Table 2. From the last row in that table, we see that the number of SSWs per year is 0.62 . This number is somewhat larger than the often quoted frequency of one SSW every two years (Andrews et al. 1985), and closer to two SSWs every three years. The ERA-40 dataset has a slightly greater frequency of SSWs than the NCEP-NCAR dataset. As expected, most of the differences between the two

\footnotetext{
${ }^{5}$ We tested the sensitivity of our algorithm by changing the tunable parameters and found relatively small sensitivity to their choice. The largest differences occurred when changing $n_{C}$. As $n_{C}$ is increased, small-scale features in the $\zeta_{p}$ field became more prominent, and the number of differences between the algorithm and the subjective analysis increases by one or two sudden warmings.
}

datasets occur at the start of the analysis period (195870); after 1970, if a SSW occurs in one dataset but not in the other, the zonal mean zonal winds are severely reduced in the dataset where the SSW does not occur, even though they fail to become easterly.

The ratio of vortex displacements to vortex splits is found to be 1.18: nearly half of the SSWs are vortex splits. Finally, in the last two columns of Table 2, we offer a simple measure of the typical strength of SSWs. The quantity $\Delta T_{10}$ is the area-weighted polar cap $\left(90^{\circ}-\right.$ $50^{\circ} \mathrm{N}$ ) mean temperature anomaly at $10 \mathrm{hPa}$, averaged \pm 5 days around the central date of each SSW. As can be seen in Table 2, vortex splits produce slightly stronger polar cap warming than vortex displacements. A more detailed comparison of the amplitude of vortex splits and displacements is given in section 5.

Before proceeding, a legitimate concern needs to be addressed: given the relatively short length of the datasets, less than $50 \mathrm{yr}$, one may wonder about the robustness of the numbers we have just presented, regarding the frequency and type ratio of SSWs. If we restrict our analysis to the winters of 1978/79 to 2001/02 (the years for which large amounts of satellite data are included in the reanalysis), the frequency of SSWs remains approximately the same: $5.8 \mathrm{SSWs}$ per decade in the NCEP-NCAR dataset and $6.7 \mathrm{SSWs}$ per decade in the ERA-40 dataset; however, the ratio of vortex displacements to vortex splits changes substantially to 1.8 in the NCEP-NCAR dataset and 1.7 in the ERA-40 dataset. We are therefore relatively confident about our values for the frequency, but less so about the ratio of vortex displacements to vortex splits. Second, one may fear that due to the recent clustering of cold winters in the early to mid-1990s and warm winters in the early 2000s (Manney et al. 2005) the choice of final year may strongly influence our climatology. To test for this, we have redone our analysis while varying the end point of our datasets (and particularly the NCEPNCAR dataset that covers the recent warm period). Some sensitivity was found, but both the frequency and type ratio of SSWs varied by only small amounts.

\section{Distribution of SSWs by month and year}

In this section we consider the temporal distribution of SSWs, the second question we posed in the introduc- 
tion. Figure 2 shows, by month, the seasonal distribution of all SSWs, vortex displacements, and vortex splits, in both datasets. SSWs in the NCEP-NCAR dataset are shown by gray bars, and SSWs from the ERA-40 dataset are shown by black bars. In both datasets the bars are normalized by dividing by the total number of SSWs, so that the abscissa shows the relative frequency of SSWs.

From the distribution of all SSWs (Fig. 2a) one may conclude that, typically, most SSWs occur during midto late winter (January-February), with only a few SSWs occurring in November and December, and no midwinter warmings after March. While the distribution of the vortex displacements does not appear to have a significant seasonality (Fig. 2b), it is clear that the distribution of vortex splits is peaked in January and February (Fig. 2c), when the vortex is radiatively strongest. SSWs at the start of winter are generally referred to as Canadian warmings (Labitzke 1981), and all but two in the NCEP-NCAR dataset and one in the ERA-40 dataset are vortex displacements (see Fig. 2b). The amplitude of SSWs (Fig. 2d) is largely constant throughout midwinter, November to February, but is markedly reduced in March. The mean amplitude of SSWs in March is approximately half that in December and January.

Figure 3 shows the yearly distribution of SSWs over the 1958-2002 period, grouped in 5-yr bins. Little trend is apparent either in the total number of SSWs or in the number of SSWs of a particular type. An apparent trend toward a reduction in SSW activity during the mid-1990s (Pawson and Naukojat 1999) has not continued in the early years of the twenty-first century. In fact, the five years between 1998 and 2002 were one of the most active periods of the last $50 \mathrm{yr}$, only surpassed in number of SSWs by the late 1960s/early 1970s. Recent work by Manney et al. (2005) has shown that the period between 1998 and 2004 has the highest SSW activity of any period on record.

Most of the interannual variability in the number of SSWs appears to be in the number of vortex displacements, while the number of vortex splits is relatively constant. There is a slight increase in the amplitude of SSWs (Fig. 3d), at least in the NCEP-NCAR reanalysis, in the 1980s and 1990s. We speculate that this trend might, at least partially, be due to the increased amount of observations of the stratosphere from satellite platforms over the second half of the dataset. In the NCEPNCAR reanalysis the mean amplitude for SSWs occurring before 1979 is $5.5 \mathrm{~K}$ while the mean amplitude for SSWs occurring in or after 1979 is $9.2 \mathrm{~K}$. This difference (3.7 K) should be compared to the standard deviation for SSWs before 1979 of $3.5 \mathrm{~K}$, and after 1979 of $4.2 \mathrm{~K}$. (a) All Events

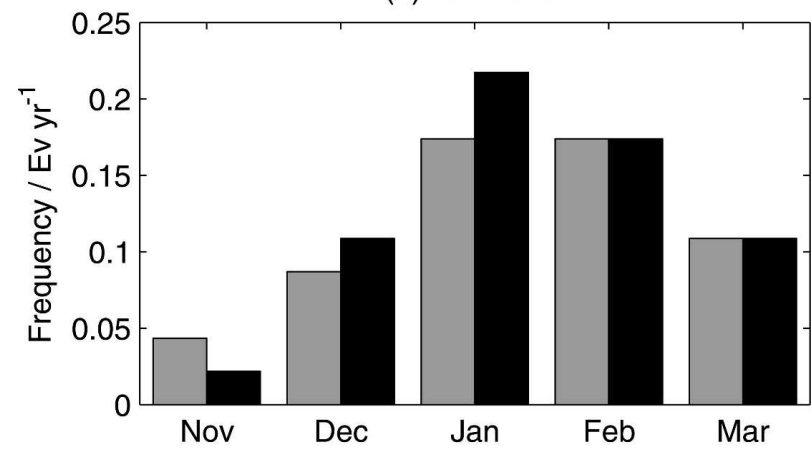

(b) Vortex Displacement Events

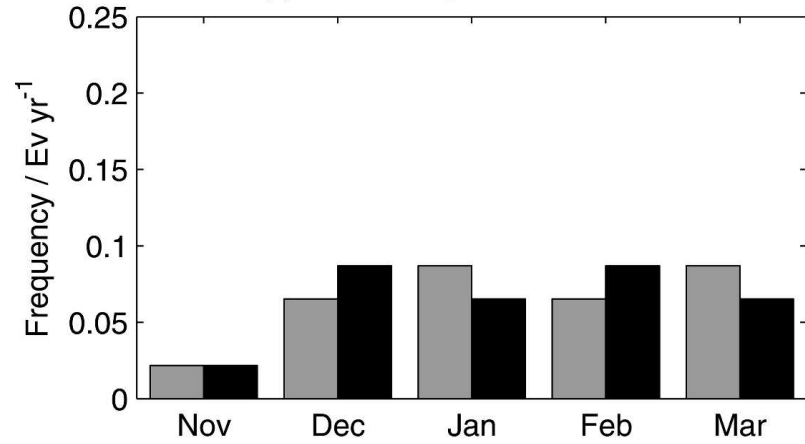

(c) Vortex Splitting Events

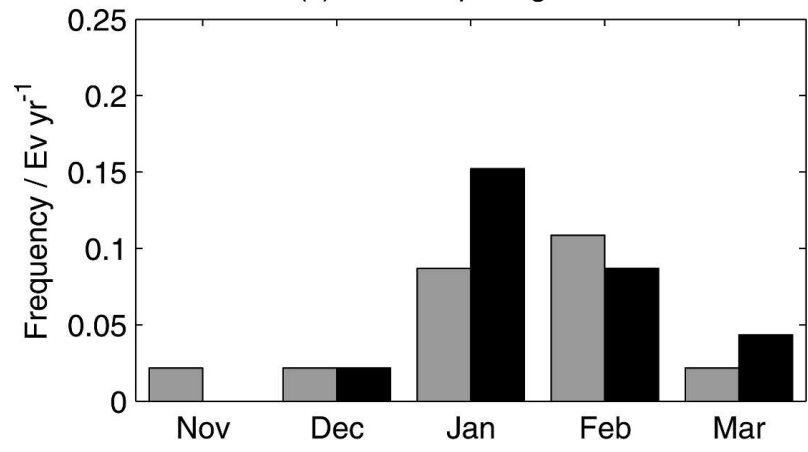

(d) Amplitude of All Events

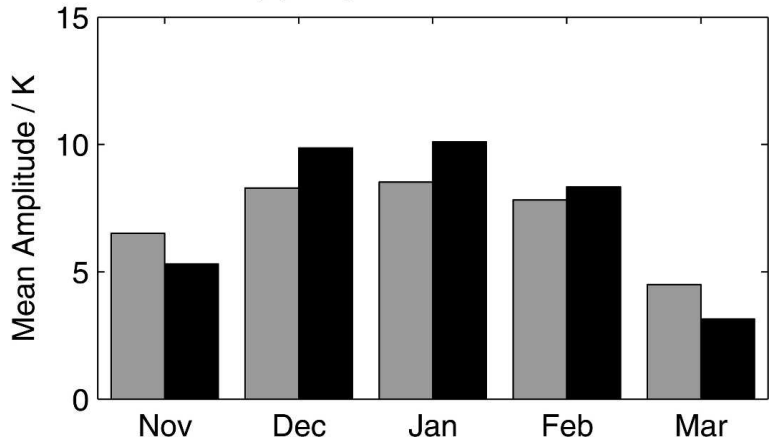

FIG. 2. Distribution of stratospheric warmings by month in NCEP-NCAR reanalysis (gray bars) and ERA-40 datasets (black bars): (a) all SSWs, (b) vortex displacements, (c) vortex splits, and (d) mean area-weighted polar cap $\left(90^{\circ}-50^{\circ} \mathrm{N}\right)$ temperature anomaly at $10 \mathrm{hPa}, \pm 5$ days from the central warming date. 
(a) All Events

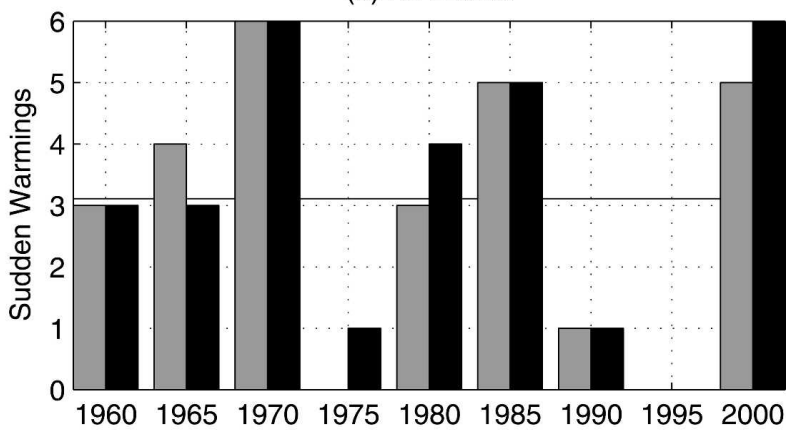

(b) Vortex Displacement Events

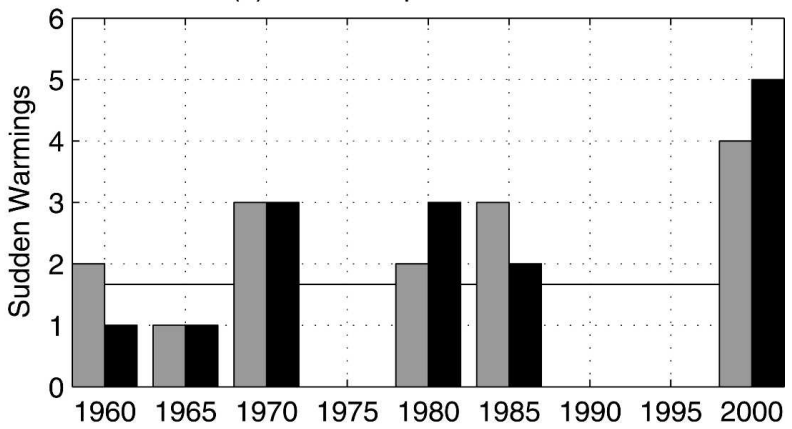

(c) Vortex Splitting Events

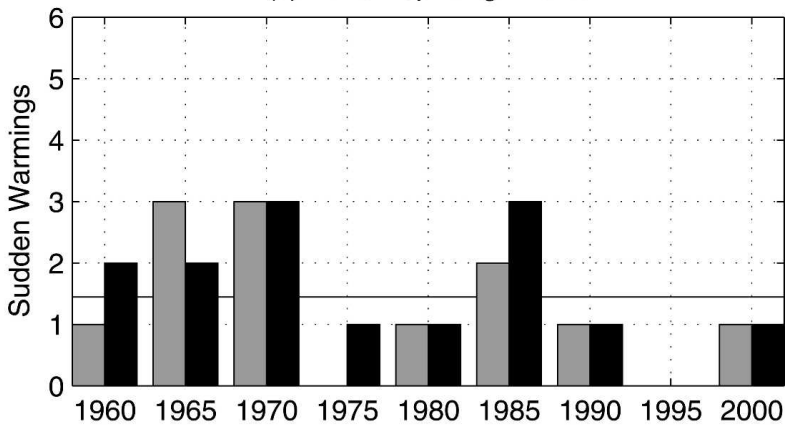

(d) Amplitude of All Events

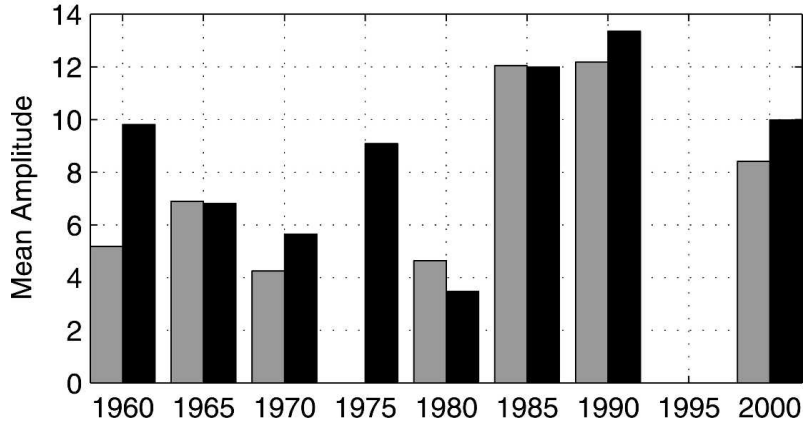

FIG. 3. Distribution of stratospheric warmings by winter season in NCEP-NCAR reanalysis (gray bars) and ERA-40 datasets (black bars). Diagnostic shows number of SSWs in 5-yr bins. (a) All SSWs, (b) vortex displacements, and (c) vortex splits. Solid line in (a), (b), and (c) shows mean number of SSWs in 5-yr period (NCEP-NCAR and ERA-40 combined). (d) Mean area-weighted polar cap $\left(90^{\circ}-50^{\circ} \mathrm{N}\right)$ temperature anomaly at $10 \mathrm{hPa}, \pm 5$ days from the central warming date.

\section{Dynamical differences between vortex displacements and splits.}

Having discussed the time distribution of SSWs, we now address the question of whether the two types of events, vortex displacement and vortex splitting, exhibit important dynamical differences. For this purpose we consider, in turn, the evolution of temperature, zonal wind, and eddy fluxes, in each of the following subsections. For the sake of brevity we restrict our analysis to the NCEP-NCAR dataset. In the following section anomalies or anomaly refers to the difference between a given quantity and its climatology. Because of the difference in seasonality of the vortex displacement and vortex splitting events, we also recalculated all the diagnostics in this section for SSWs that occur in NDJF only. There was no qualitative difference in the results when SSWs that occur in March were excluded.

\section{a. Polar temperature}

Figure 4a shows composites of the evolution, during SSWs, of area-weighted polar cap temperature anomalies at $10 \mathrm{hPa}$. The composite anomaly for vortex displacements is shown by the solid line, and for vortex splits by the dashed line. Shaded regions show where the polar cap temperature anomaly is significantly different between the two types of SSWs, at the 0.10 confidence level. Statistical significance is calculated using a standard $t$ test (Wilks 1995).

As expected, the SSW is concurrent with a large increase in the temperature of the polar cap in the middle stratosphere, distributed almost symmetrically about the central date, for both vortex displacements and vortex splits. However, there appears to be no significant difference between the peak polar cap temperature anomaly for vortex displacements and vortex splits. This confirms the result in Table 2, where the temperature anomaly for vortex splits was found to be only about one degree larger than that for vortex displacements. This is counter to our expectation that vortex splits would produce larger temperature anomalies in the middle stratosphere, as they are accompanied by a more substantial disturbance of the flow required to split the vortex. Small patches of significant difference between the vortex displacement and splitting composites occur in the growth and decay phases of the SSW when polar cap temperatures are anomalously cold. Most markedly the decay phase of the SSW in the vortex splitting composite shows much larger cold anomalies, which last longer than the vortex displacement composite.

To examine the structure of the SSWs in the lower stratosphere, we plot similar composites of polar cap 
(a) Polar Cap (90-50N) Temperature Anomaly $10 \mathrm{hPa}$

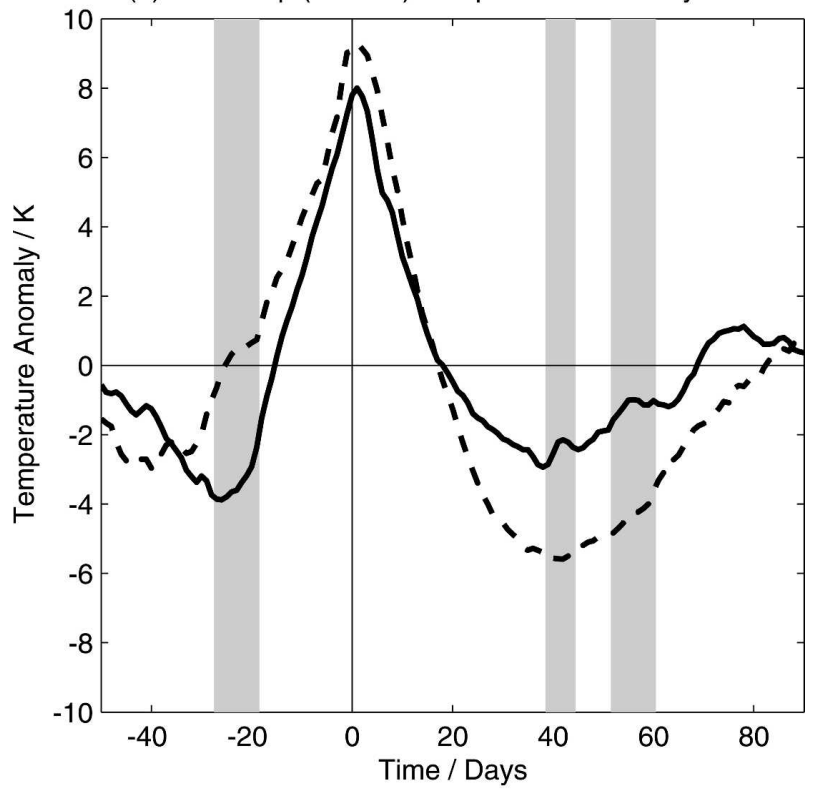

(b) Polar Cap (90-50N) Temperature Anomaly 100hPa

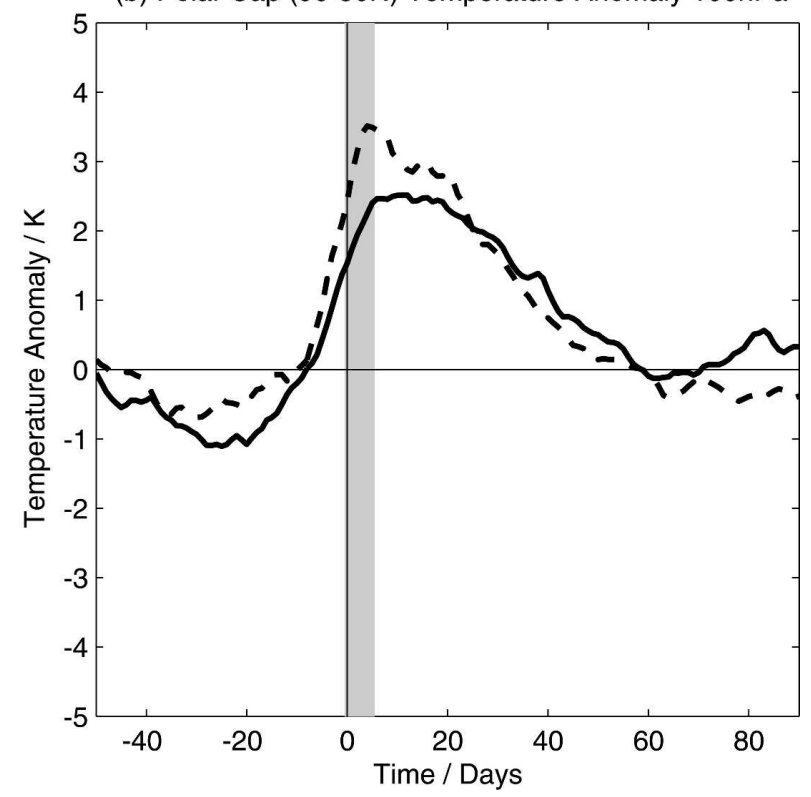

FIG. 4. Polar cap temperature $\left(90^{\circ} \mathrm{N}-50^{\circ} \mathrm{N}\right)$ anomaly at $10 \mathrm{hPa}$ for vortex displacements (solid line) and vortex splits (dashed line). Gray shading indicates that the anomaly is significantly different for vortex displacements and vortex splits at 0.10 confidence, (a) for 10-hPa pressure surface and (b) for 100-hPa pressure surface.

temperature anomalies at $100 \mathrm{hPa}$ (Fig. 4b). In the lower stratosphere, SSWs are also characterized by a large temperature anomaly concurrent with the temperature peak in the middle stratosphere; however, at this level, the vortex splitting composite has significantly larger temperature anomalies than the vortex displacement composite. Following the SSWs, temperature anomalies in the lower stratosphere decay much more slowly than at $10 \mathrm{hPa}$, lasting up to 50 days after the warming. This is consistent with the difference in radiative damping time scales of the order of 10 days in the middle stratosphere and 40 days in the lower stratosphere (Newman and Rosenfield 1997). However, unlike in the middle stratosphere, there appears to be little significant difference between the two types of SSWs at $100 \mathrm{hPa}$ in their decay phase. It should also be noted that one would expect some small regions of significance to occur as false positives given the 0.10 confidence level of our test. In summary, the evolution of $100-\mathrm{hPa}$ temperature structure in the vortex displacement and splitting composites is remarkably similar.

Before discussing the evolution of zonal winds during SSWs we wish to emphasize that, surprisingly, the impact of SSWs on the mean wintertime polar cap temperature of the stratosphere is relatively small. One might, perhaps naively, suspect that there would be some correlation between the occurrence of SSWs, the winter mean polar cap temperature, and the corresponding winter mean heat flux at $100 \mathrm{hPa}$. The relationship between winter mean polar cap temperature and winter mean heat flux has been well established by a number of studies (Fusco and Salby 1999; Newman et al. 2001; Hu and Tung 2002). An obvious question then arises: are winters in which SSWs occur anomalously warm? As shown in Fig. 5, this is not the case. In terms of both the winter temperatures in the middle stratosphere (on the abscissa) and the amount of wave activity entering the stratosphere over the same winter (on the ordinate) it is not possible to differentiate between years with an SSW (dots) and those without (crosses). This result can be understood by considering the evolution of the polar cap temperature during SSWs. As can been seen from Fig. 4a, for both vortex displacements and vortex splits, the temperature anomaly at 10 $\mathrm{hPa}$ integrates to a relatively small number over the life cycle of the stratospheric warming. Hence, the presence of an SSW leaves little signature on the mean temperature for the corresponding winter. Finally we note that, in spite of the different definition of what constitutes an SSW, the evolution of polar cap temperature anomalies presented here is broadly consistent with the evolution of polar cap temperature anomalies reported in LIM04.

\section{b. Zonal wind}

Next we consider the evolution of the zonal mean zonal wind during SSWs. Figure 6 shows the area-weighted mean polar cap $\left(90^{\circ}-60^{\circ} \mathrm{N}\right)$ zonal wind anomaly as a function of pressure and time, composited for vortex displacements (Fig. 6a) and vortex splits (Fig. 6b). The 


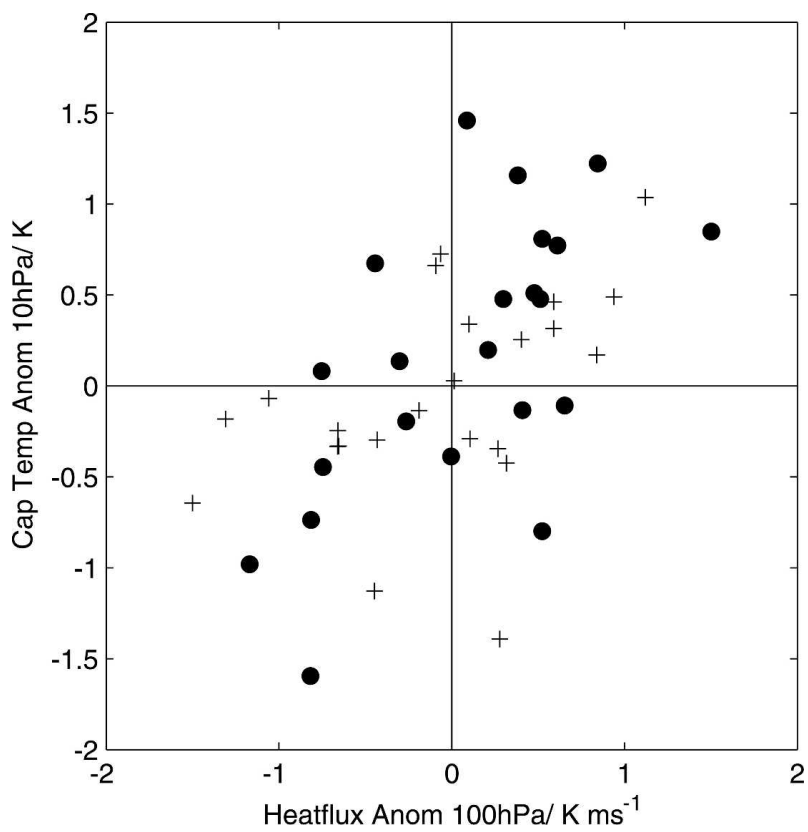

FIG. 5. Scatterplot showing winter anomaly polar temperature at $10 \mathrm{hPa}\left(\right.$ averaged over $\left.90^{\circ}-50^{\circ} \mathrm{N}\right)$ and winter meridional heat flux anomaly at $100 \mathrm{hPa}$ (averaged over $90^{\circ}-50^{\circ} \mathrm{N}$ ). Years that have at least one stratospheric warming are plotted with dots and years that do not have any stratospheric warmings are plotted with crosses.

difference between the two types of SSWs is shown in Fig. 6c, where gray shading is used to highlight the regions of statistically significant differences, at the 0.10 confidence level, calculated with a $t$ test.

From the lower panel, it is clear that most of the difference between vortex displacements and vortex splits occurs prior to and around the central date. In general, the wind deceleration that accompanies each SSW (blue contours in Figs. 6a,b) is stronger and more sudden in the case of vortex splits, and it also extends deeper.

To bring out the structure of these zonal mean zonal wind anomalies, composites of the latitude-pressure zonal mean zonal winds prior to, during, and following the SSWs are shown in Fig. 7; the top and middle rows correspond to vortex displacements and vortex splits, respectively, while the bottom row shows the difference. These plots can be directly compared with those in Fig. 3 of LIM04.

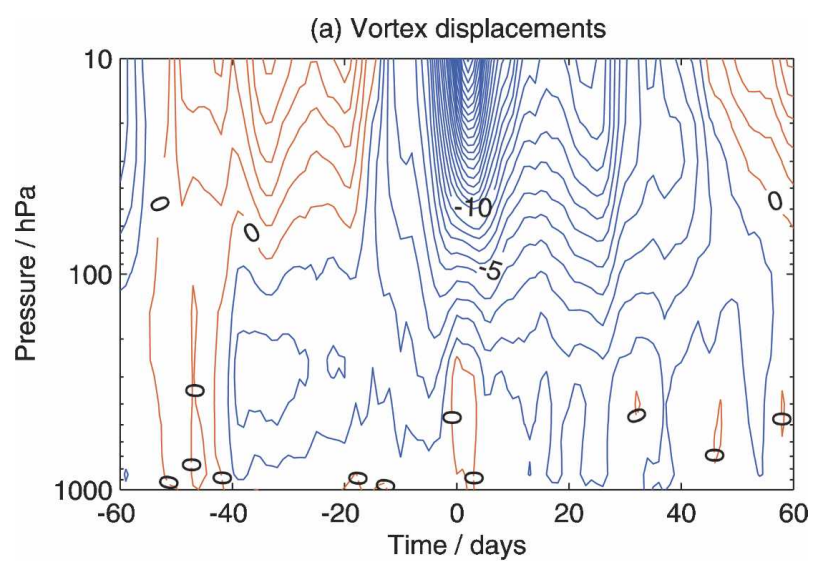

(b) Vortex Splits

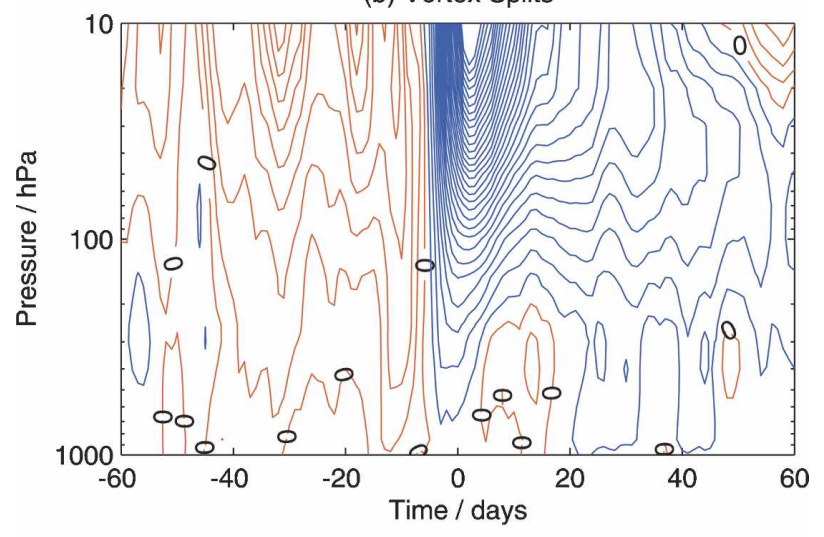

(c) Difference

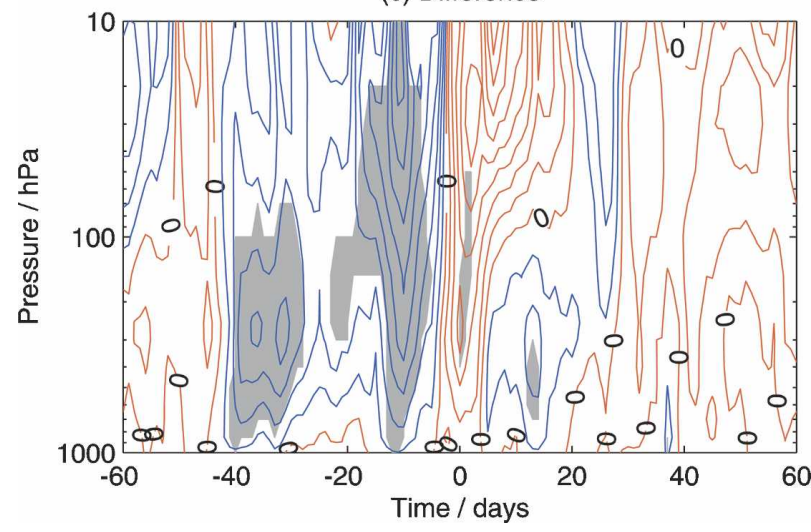

Fig. 6. Area-weighted zonal mean zonal wind anomaly at $60^{\circ}-$ $90^{\circ} \mathrm{N}$. Contour interval in all plots is $1 \mathrm{~m} \mathrm{~s}^{-1}$. Blue contours show negative anomalies; red contours show positive anomalies. (a) Vortex displacements, (b) vortex splits, and (c) the difference. Shading in (c) indicates that the difference is significant at the 0.10 confidence level. Contour interval is $1 \mathrm{~m} \mathrm{~s}^{-1}$.

FIG. 7. Time mean zonal mean zonal wind anomalies. Contour interval is $0.5 \mathrm{~m} \mathrm{~s}^{-1}$. Blue contours show negative anomalies; red contours show positive anomalies. Shading shows that difference is significant at 0.10 confidence level. (a) Anomalies averaged -20 to -6 days for vortex displacements; (b) same as in (a), but for -5 to 20 days; (c) same as in (a), but for 21 to 40 days; (d)-(f) same as in (a), (b), and (c), but for vortex splits; and (g)-(i) difference between (a)-(c) and (d)-(f). 
(a) Displacements -20 to -5

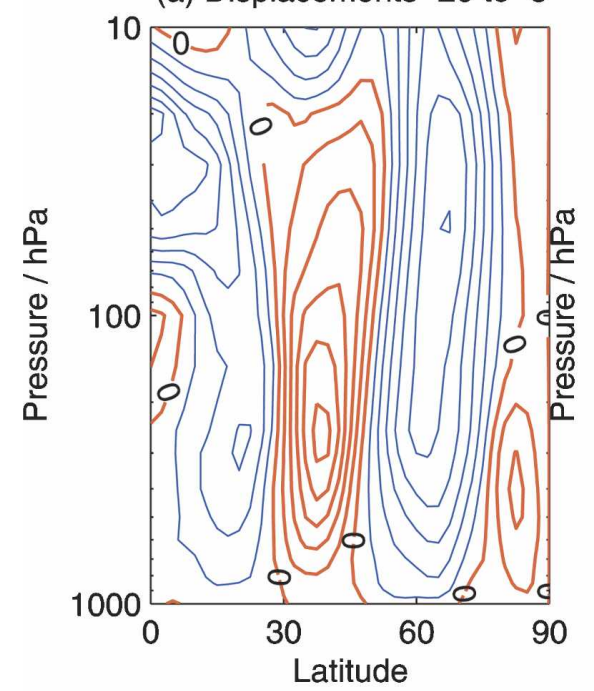

(d) Splits -20 to -5

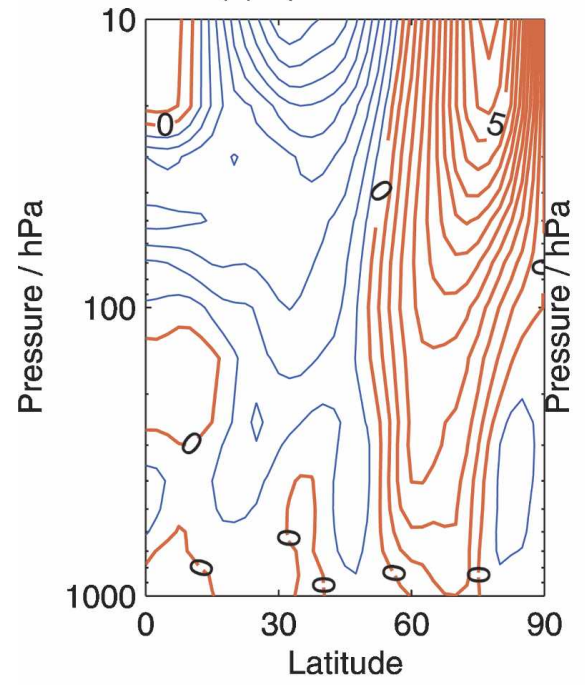

(g) Difference -20 to -5

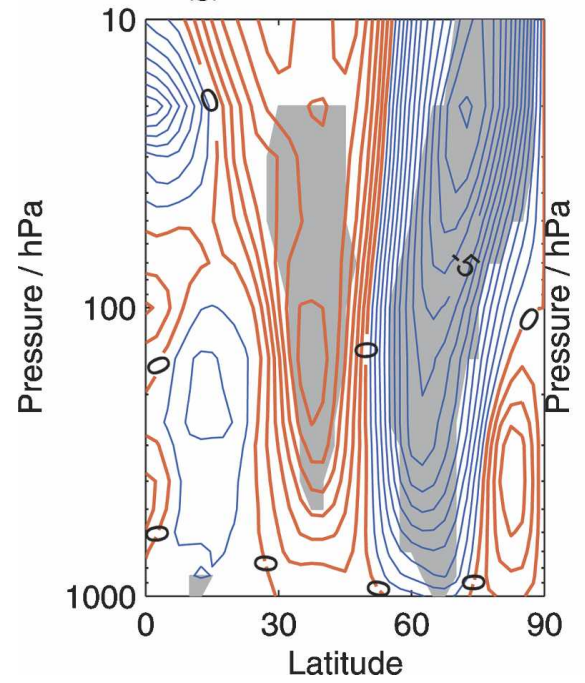

(b) Displacments -5 to 20

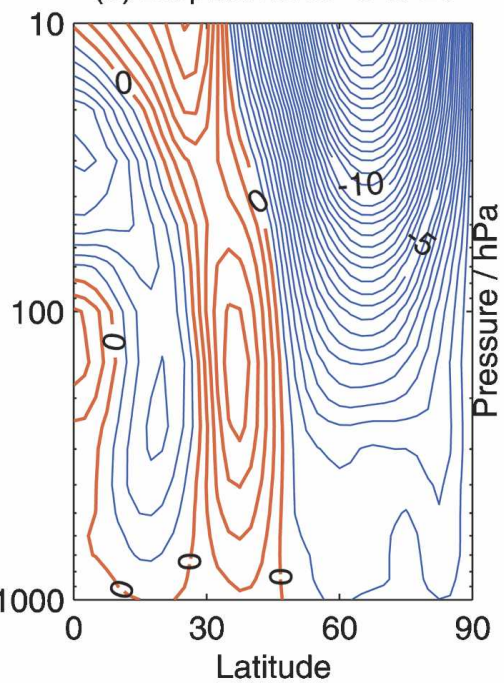

(e) Splits -5 to 20

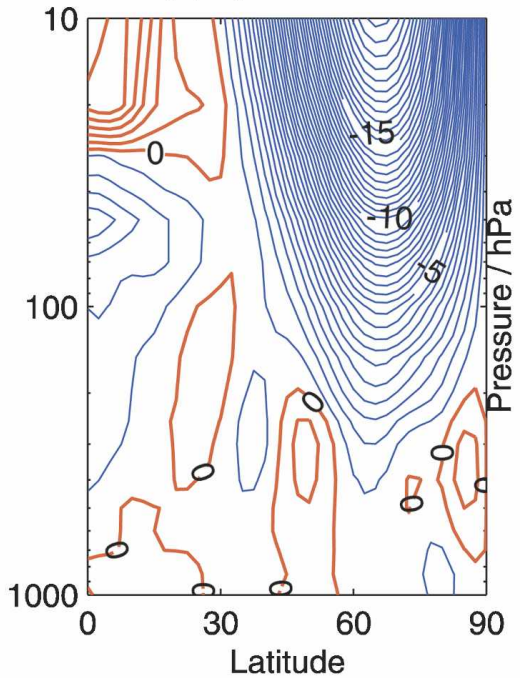

(h) Difference -5 to 20

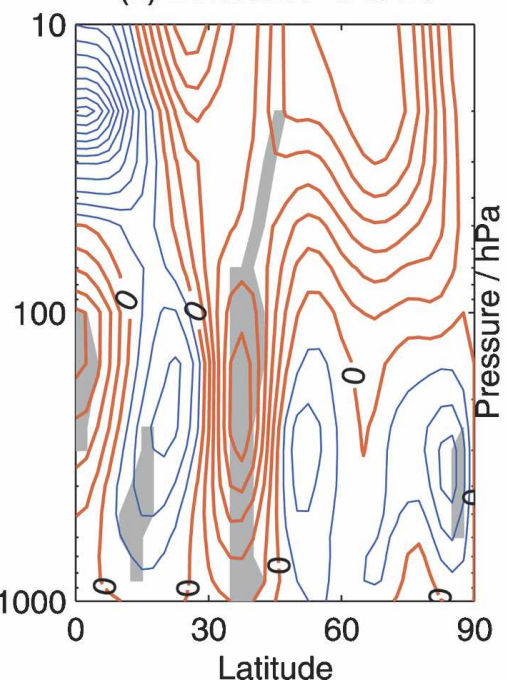

(c) Displacements 20 to 40

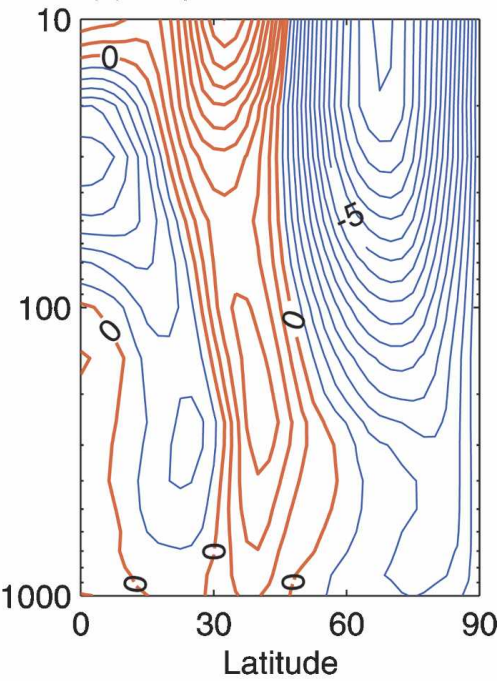

(f) Splits 20 to 40

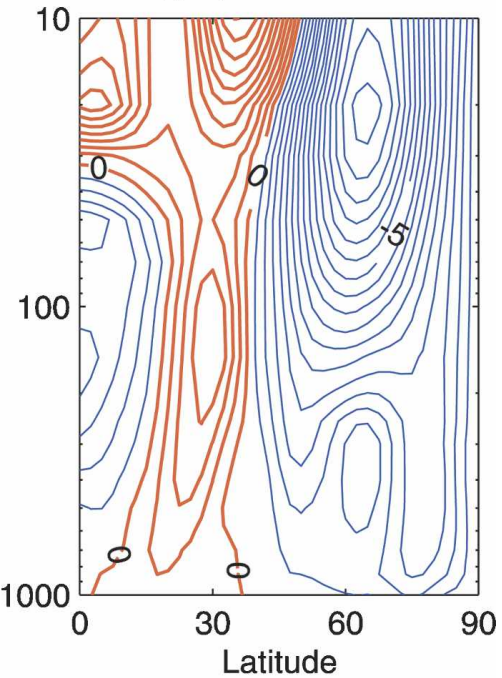

(i) Difference 20 to 40

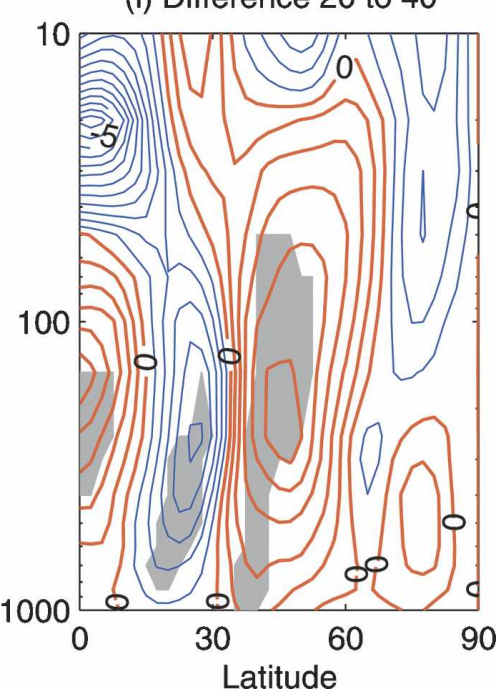


Prior to the SSW (Fig. 7, left column) the largest differences between the vortex displacements and vortex splits are found. A large positive zonal mean zonal wind anomaly in the vortex splitting composite (Fig. $7 \mathrm{~d}$ ), centered at $70^{\circ} \mathrm{N}$, extends throughout the stratosphere and troposphere, while a much weaker and more negative anomaly is found in the same region for the vortex displacement composite. The composite structure shown in LIM04, which includes both types of SSWs, is unable to capture this distinction.

The zonal mean zonal wind anomalies in the vortex splitting composite are consistent with the idea of a "preconditioning" of the stratospheric flow prior to an SSW (McIntyre 1982). A preconditioned stratospheric vortex would be weak and small, as shown by the positive anomalies north of the normal position of the stratospheric jet in Fig. 7d. This figure suggests that the preconditioning extends into the upper troposphere and is absent in the vortex displacements. Recent work using simple dynamical models (Scott et al. 2004) has shown that the upward propagation of planetary waves in the stratosphere is enhanced by steep gradients of potential vorticity. Positive zonal mean zonal wind anomalies suggest that the presence of stronger PV gradients, even in the upper troposphere, might be important for the occurrence of vortex splits.

During the SSW (Fig. 7, middle column) large negative zonal mean zonal wind anomalies are found poleward of $50^{\circ} \mathrm{N}$ in the stratosphere, denoting the strong deceleration of the vortex that accompanies both types of SSW. In addition, for vortex displacements, positive anomalies occur between $50^{\circ}$ and $30^{\circ} \mathrm{N}$ and extend all the way into the troposphere (Fig. 7b). This structure is consistent with the composites shown in LIM04 and corresponds to an equatorward shift of the tropospheric jet. For the vortex splitting composite, little coherent structure emerges in the troposphere during this period.

Finally, in the decay phase of the SSW (Fig. 7, right column) the anomaly structure that develops in the vortex splitting composite (Fig. 7f) is quite similar to that in the vortex displacement composite in the previous period (Fig. 7b). Meanwhile, the negative tropospheric anomalies in the vortex displacement composite associated with the SSW have become much weaker and moved poleward (Fig. 7c). Therefore, in terms of the zonal mean zonal wind response of the troposphere, both types of SSW have similar impacts, albeit somewhat delayed in the vortex splitting composite.

\section{c. Eddy fluxes}

In this section we consider the changes to the eddy forcing in the stratosphere and troposphere prior to and

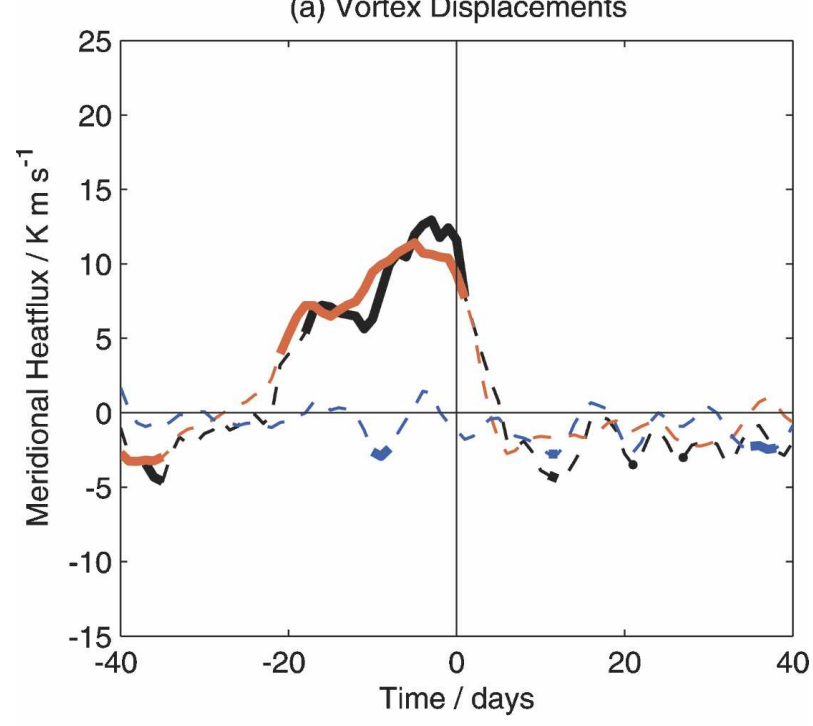

(b) Vortex Splits

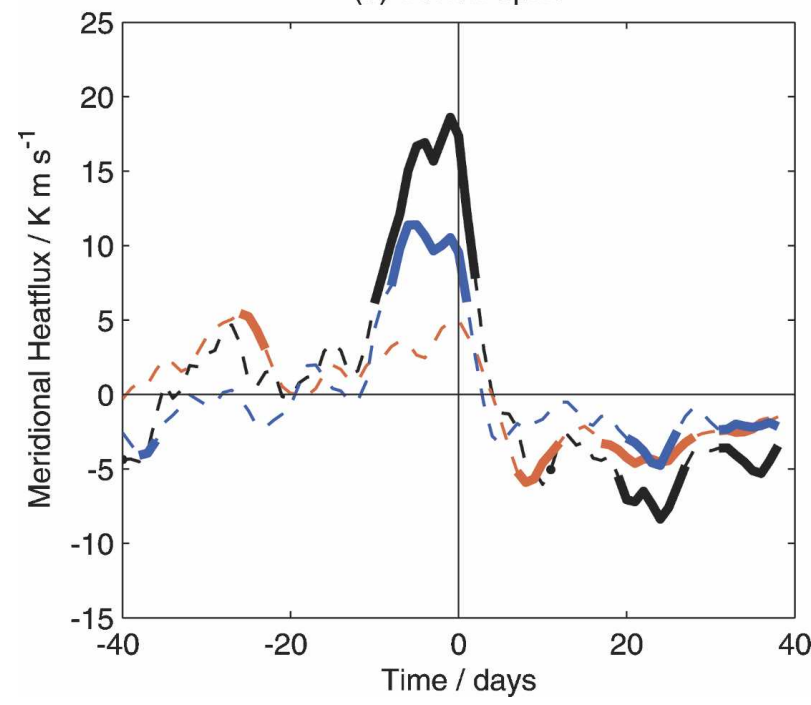

FIG. 8. Composite area-weighted meridional heat flux anomaly at $45^{\circ}-75^{\circ} \mathrm{N}$ on the $100-\mathrm{hPa}$ pressure surface. Black line shows total anomalous meridional heat flux, red line shows anomalous meridional heat flux due to zonal wavenumber 1 , and blue line shows anomalous meridional heat flux due to zonal wavenumber 2. Solid portions of each line show that the mean heat flux is significantly different from zero at the 0.10 confidence level. (a) Vortex displacements and (b) vortex splits.

following the SSW. Following other studies (e.g., Polvani and Waugh 2004) Fig. 8 shows the meridional heat flux anomaly averaged at $45^{\circ}-75^{\circ} \mathrm{N}$ for all wavenumbers (black line), zonal wavenumber 1 (red line), and zonal wavenumber 2 (blue line). Solid portions of each line indicate that the anomaly is significantly greater than zero at 0.10 confidence, calculated with a $t$ test. The meridional heat flux is directly proportional to 
(a) Displacements 0 to 20

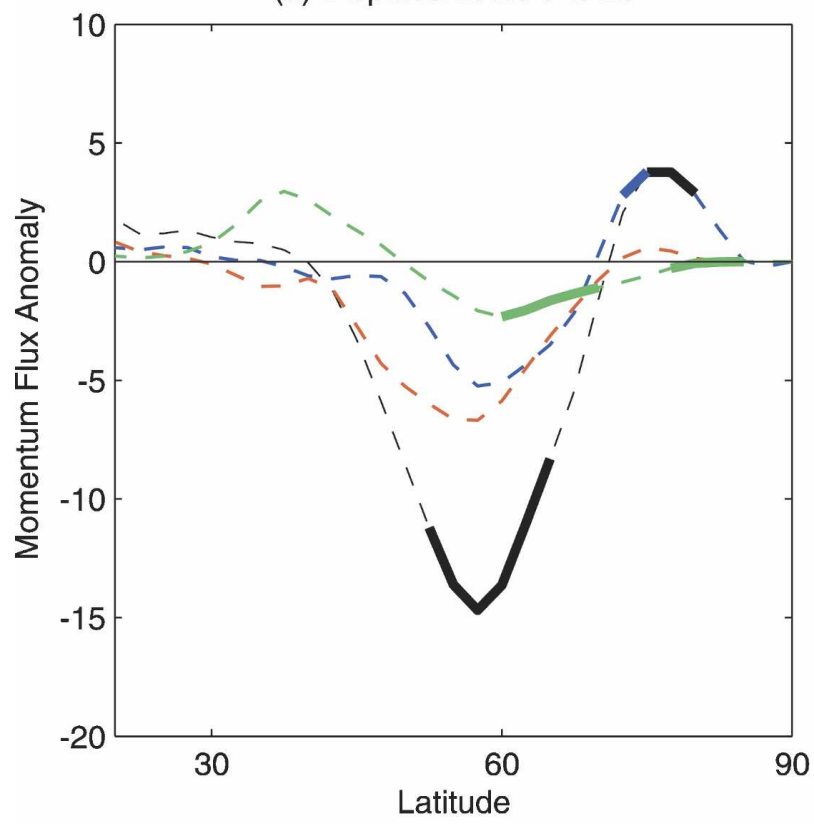

(c) Displacements 20 to 40

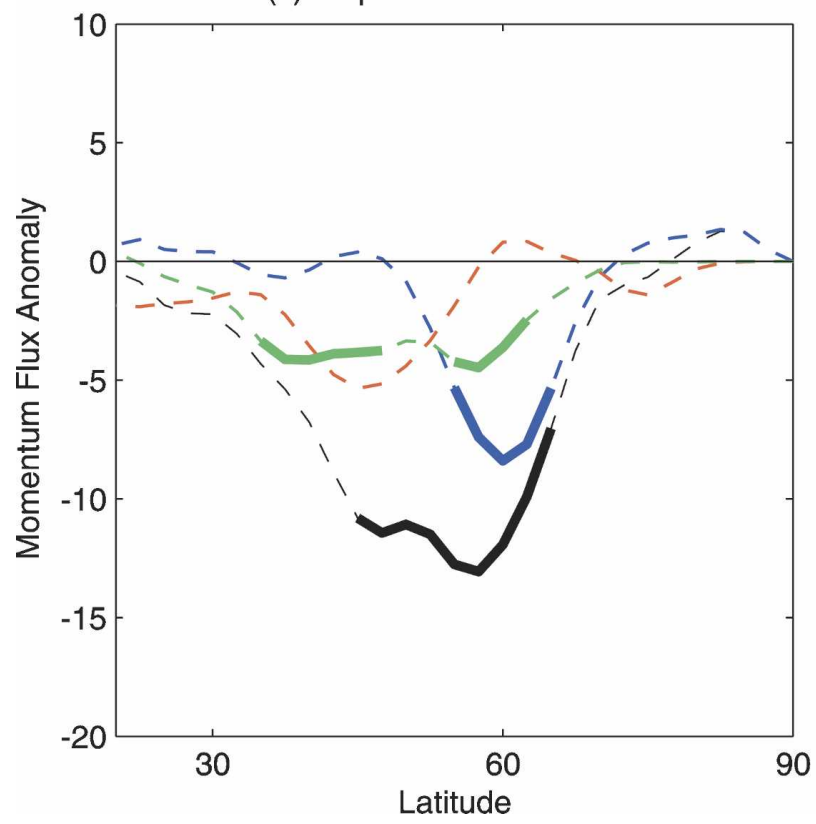

(b) Splits 0 to 20

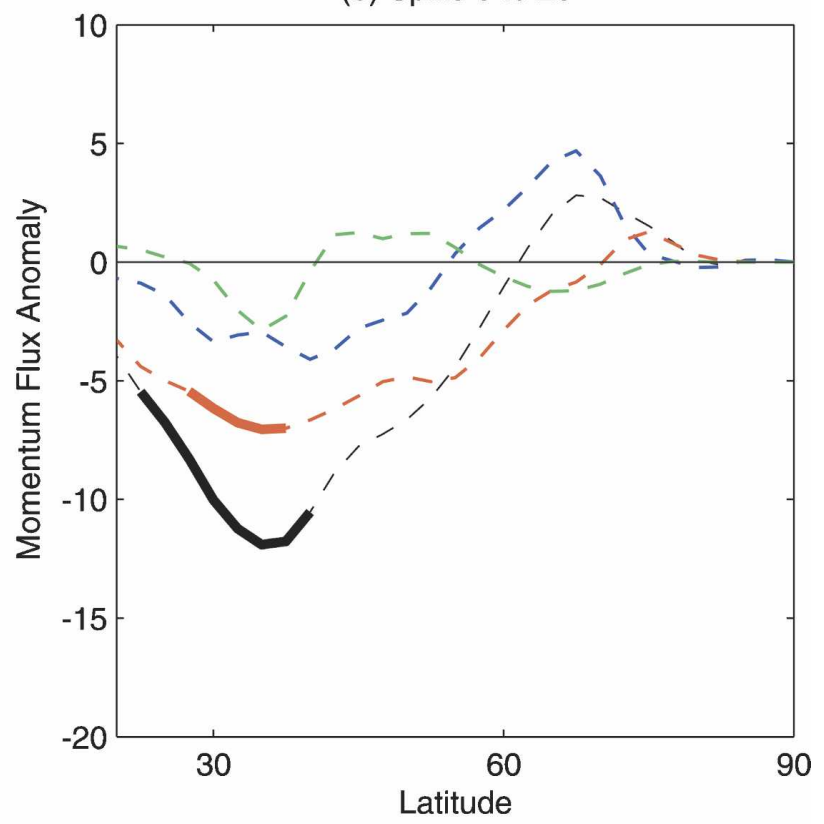

(d) Splits 20 to 40

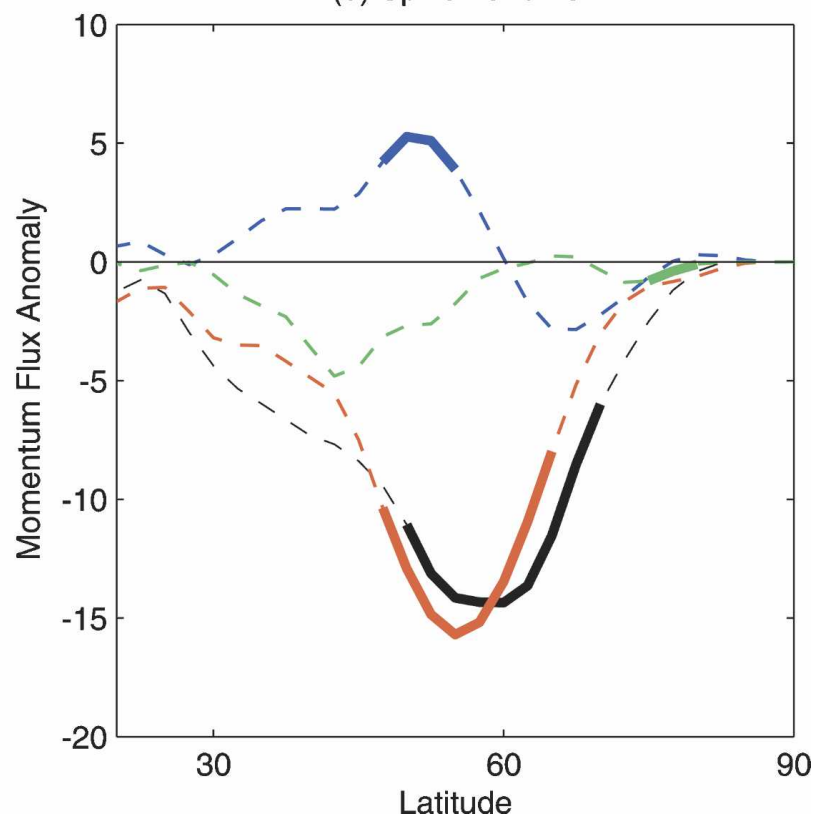

FIG. 9. Time mean meridional momentum flux anomaly at $300 \mathrm{hPa}$ as a function of latitude. Black line shows total momentum flux anomaly, blue line shows sum of zonal wavenumber 1 and 2 components, red line shows sum of zonal wavenumber 3 and 4 components, and green line shows sum of zonal wavenumber 5,6 , and 7 components. Solid portions of all lines indicate statistical significance at 0.10 confidence, (a) for vortex displacements averaged 0 to 20 days following the warming; (b) same as in (a), but for vortex splits; (c) for vortex displacements 20 to 40 days following the warming; and (d) same as in (c), but for vortex splits.

the vertical component of the Eliassen-Palm flux (Andrews et al. 1985).

In the vortex displacements (Fig. 8a) anomalous wave activity begins 20 days before winds in the stratosphere become easterly. Almost all of the heat flux throughout the warming is due to the zonal wavenumber 1 component. Following the SSW there are no significant heat flux anomalies. In contrast, in the vortex splitting composite (Fig. 8b) there is some evidence of a "precursor" heat flux anomaly 30 days before the 
central date (which is almost completely due to the zonal wavenumber 1 component) followed by a second, larger heat flux anomaly 10 days before the central date (which is mostly due to the zonal wavenumber 2 component). Following the SSW there are significant negative heat flux anomalies, indicating suppressed vertical fluxes of planetary waves, particularly in the zonal wavenumber 1 component. The suppression of planetary wave activity following the SSW in the vortex splitting composite is likely related to the positive polar cap temperature anomalies in Fig. 4b. Neither the vortex displacement or vortex splitting composites have a similar structure to the vertical Eliassen-Palm flux composite of LIM04 (their Fig. 10d).

LIM04 showed that following SSWs the largest changes to the wave forcing in the troposphere occur in the meridional component of the Eliassen-Palm flux at zonal wavenumbers 3 and above. The meridional component of the Eliassen-Palm flux can be approximated by the meridional momentum flux. Negative momentum flux anomalies in the upper troposphere decelerate the zonal flow at the position of the anomaly and produce dipolar anomalies in the surface pressure field (Vallis et al. 2004).

Figure 9 shows the time-averaged momentum flux anomalies at $300 \mathrm{hPa}, 0$ to 20 days (top row) and 20 to 40 days (bottom row) following the central date; the composites for vortex displacements are in the left column, and those for vortex splits in the right column. In each panel, the total anomaly is shown in the black line, while the contributions from wavenumbers $1-2,3-4$, and 5-7 are shown by the blue, red, and green lines, respectively. Solid portions of each line indicate that the anomaly is significantly greater than zero at 0.10 confidence, calculated with a $t$ test.

For the vortex displacement composite, there are large negative momentum flux anomalies centered around $60^{\circ} \mathrm{N}$ following the event (Figs. 9a,c). The location of the momentum flux anomalies corresponds well with the location of deceleration of the zonal mean zonal wind shown in Figs. 7b and 7c. Momentum flux anomalies occur in all three wavenumber bands. In contrast in the vortex splitting composite there is a marked difference in the anomalous momentum flux close to the time of the warming (Fig. 9b) and the anomalous momentum flux more than 20 days after the central date of the SSW (Fig. 9d). Close to the central date the largest momentum flux anomaly following the vortex splits is located near the subtropical jet at around $35^{\circ} \mathrm{N}$. As the SSW decays, large momentum flux anomalies associated with the extratropical jet, around $55^{\circ} \mathrm{N}$, occur, which are consistent with a deceleration of zonal mean zonal wind at $50^{\circ}-60^{\circ} \mathrm{N}$ (Fig. $7 \mathrm{e}$ ), in a manner similar to that seen in the vortex displacements. Figure $9 \mathrm{~b}$ shows that almost all of this anomalous momentum flux is due to waves of zonal wavenumber 3 and 4 .

Prior to the SSW (not shown) momentum flux anomalies are small in both the vortex displacement and vortex splitting composites. The changes to meridional momentum flux that follow the SSWs are consistent with recent work showing that baroclinic systems are sensitive to variations in the lower-stratospheric wind shear (Wittman et al. 2004, 2007).

\section{Tropospheric impact}

In this section we wish to compare the relative impact of vortex displacements and vortex splits on the tropospheric flow, to address the last question posed in the introduction. We started our analysis by first constructing time-height composites of the NAM index, as in Fig. 2a of Baldwin and Dunkerton (2001), for the two types of SSW. However, the structure of the NAM index for the two types of SSW was found to be extremely sensitive, particularly in the troposphere: the size and timing of the composite NAM index anomalies following the events could be substantially altered by adding or removing even a single event. Hence, composite time-height NAM plots could not be used to examine differences in tropospheric impact between the vortex splits and vortex displacements.

Instead, we first present composite maps of the 1000$\mathrm{hPa}$ geopotential height anomalies, composited for the two types of SSW. Following Baldwin and Dunkerton (2001), we consider the time period of 0-60 days following each event. Figure 10 shows composite geopotential height anomaly maps, at $1000 \mathrm{hPa}$, over that time period, calculated for vortex displacements, vortex splits, and their difference, respectively. In the vortex displacement composite, the familiar tropospheric sig-

FIG. 10. Mean composite 1000-hPa geopotential height anomalies 0-60 days following different types of stratospheric major warmings. Contour interval is $5 \mathrm{~m}$. Thick black contours show spatial structure of Arctic Oscillation, from data in Baldwin and Dunkerton (2001) (solid and dashed lines show 100 and -100 m values). (a) Composite for all vortex displacements. (b) Same as in (a), but for vortex splits. (c) Difference between vortex displacements and vortex splits; thick black contours denote that difference is significant at 0.1 confidence level. (d) Same as in (a), but only for vortex displacements in Baldwin and Dunkerton (2001). (e) Same as in (d), but for vortex splits. (f) Composite of (d) and (e). 

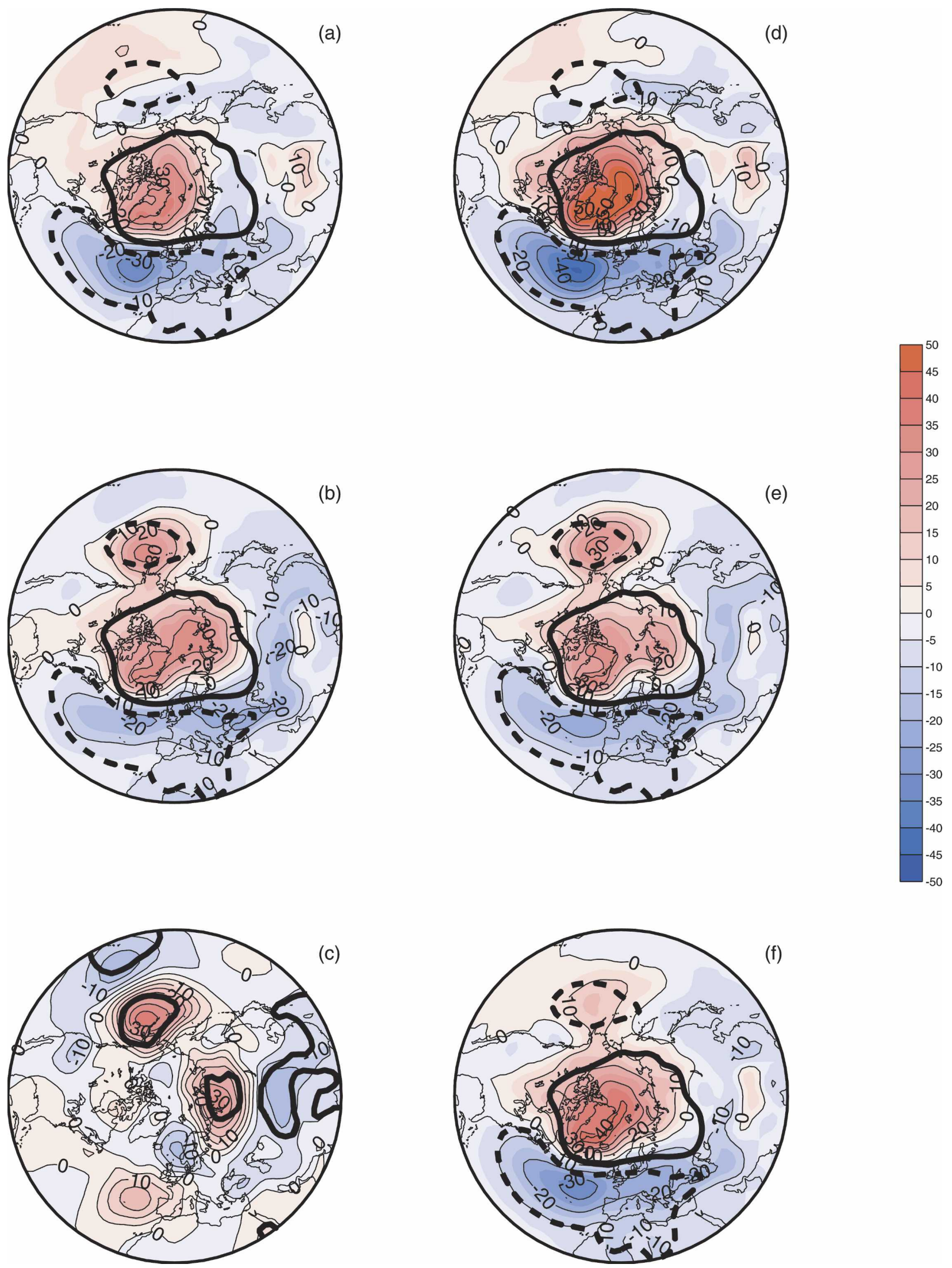
nature of SSWs is found: an increase in geopotential height over the polar cap and a reduction in geopotential height in the midlatitude North Atlantic (cf. Fig. 9 in LIM04). This structure projects strongly onto both the North Atlantic Oscillation (NAO) index and the NAM. In contrast, the geopotential height anomalies following the vortex splits have a much more global character and include positive maxima over central Eurasia and the Pacific Ocean (Fig. 10b), with the maximum in the Pacific directly over the center of action of the 1000-hPa NAM.

The difference in the tropospheric response between the two types of SSWs occurs even if SSWs that do not have a large NAM index amplitude in the stratosphere are excluded. This is illustrated in Figs. 10d and 10e, showing the averaged geopotential height anomaly composited for only those SSWs in our dataset that have crossed the -3 NAM index threshold at $10 \mathrm{hPa}$, the value used in Baldwin and Dunkerton (2001) to define ESEs. As in the composite for all SSWs, the anomaly structure following vortex displacements is strongly biased toward the Atlantic sector (Fig. 10d), while the anomaly structure following vortex splits has a much more global structure, with a reduced amplitude in the Atlantic sector (Fig. 10e).

The difference in tropospheric anomaly pattern goes at least some way to explaining the structure of the zonal mean response difference between the two SSWs and in explaining the structure of the geopotential height anomaly when both vortex displacement and splits are considered together. Figure 10f shows the average of Figs. 10d and 10e and can be directly compared with Fig. 3a of Baldwin and Dunkerton (2001). Notice, in both cases, the small positive geopotential height anomalies in the Pacific Ocean basin, which are shown here to be associated with vortex splits.

The large positive $1000-\mathrm{hPa}$ geopotential height anomalies in the Pacific sector following vortex splits are surprising and have not been observed in previous studies of the response of the NAM to stratospheric variability. To further investigate the anomaly structure in the Pacific sector, we have computed the time series of geopotential height averaged between $30^{\circ}-60^{\circ} \mathrm{N}$ and $170^{\circ}-230^{\circ} \mathrm{W}$, for vortex splits and vortex displacements (Fig. 11). The large positive anomalies during vortex splits are present up to 60 days before the central date and appear to persist throughout the warming period shown.

Because the positive geopotential height anomalies in the Pacific are present before the central date of the SSW, it is likely that they are not a response of the tropospheric flow to changes in the stratosphere. In fact, the pattern of high geopotential height anomalies

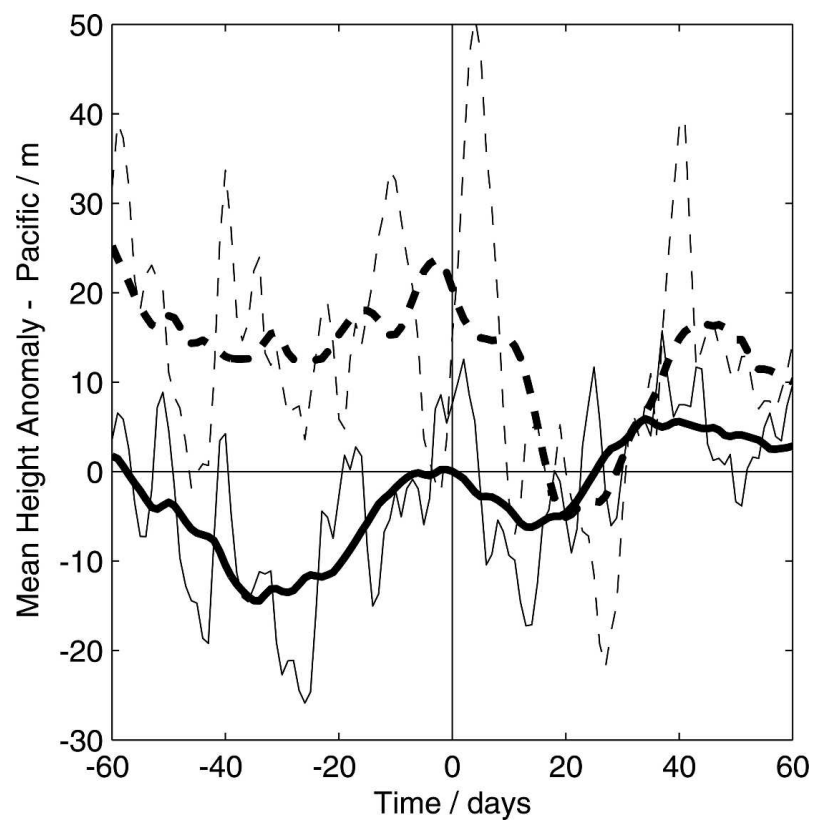

FIG. 11. Area-weighted 1000-hPa geopotential height anomaly, at $60^{\circ}-30^{\circ} \mathrm{N}, 170^{\circ}-230^{\circ} \mathrm{W}, \pm 60$ days around the central date of the stratospheric major warming. Solid lines show vortex displacement composite; dashed lines show vortex splitting composite. Thick lines show 21-day running mean composite.

in the mid-Pacific is reminiscent of the positive phase of the Pacific-North American pattern (PNA; Wallace and Gutzler 1981). Other authors have recently studied the connections between the PNA and stratospheric variability (Sassi et al. 2004, and references therein), particularly its links with the El Niño-Southern Oscillation (Taguchi and Hartmann 2006). It has been known for some time that the positive PNA is associated with large zonal wavenumber 2 anomalies in the geopotential height field in the lower stratosphere (Baldwin and O'Sullivan 1995).

Given that the anomaly patterns in the troposphere associated with vortex splits are complicated and might not all be directly related to stratospheric changes, diagnosing the relative impact of vortex displacements and vortex splits on the tropospheric flow as a whole is difficult. As already mentioned, the standard practice is to construct composite plots of NAM index around the central date. Since we found it difficult to compare the impact of different types of warmings on the troposphere using composite NAM index plots, we chose to compare the integrated NAM index at 10 and $1000 \mathrm{hPa}$ for all of the warmings.

Figure 12a shows the integrated NAM index at 10 $\mathrm{hPa}, 1-10$ days following the SSW, as a function of the day of the winter that the warming occurs. The NAM index of the vortex splits (black symbols) and vortex 
(a) NAM 10hPa 1 to 10 days

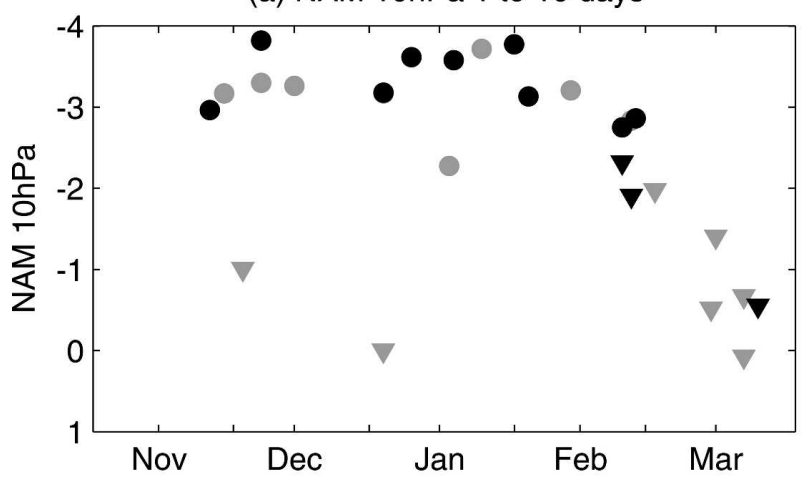

(b) NAM $1000 \mathrm{hPa} 10$ to 60 days

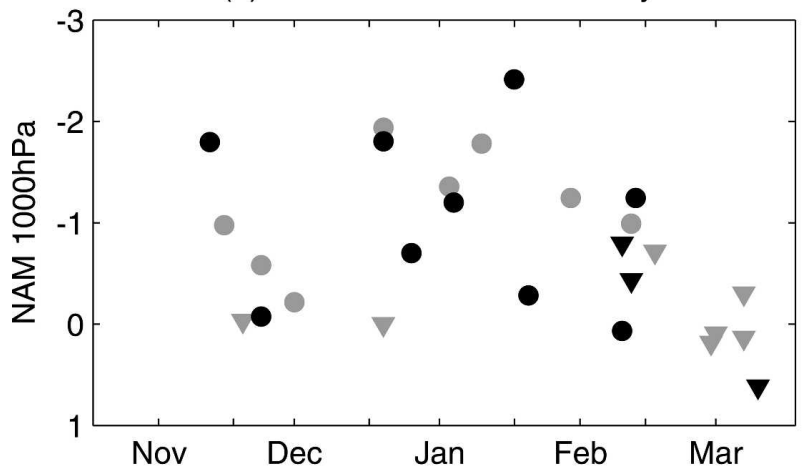

(c) NAM 10hPa vs NAM 1000hPa

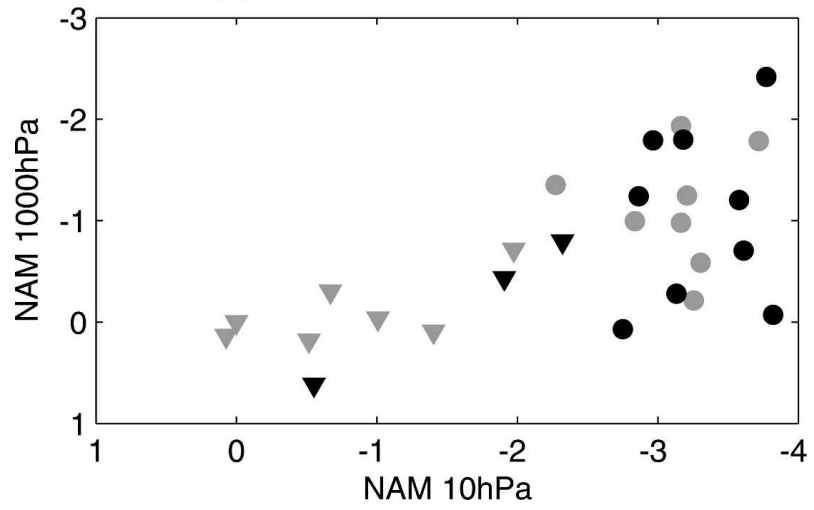

FIG. 12. Mean NAM index for each individual stratospheric warming as a function of day of the winter. Black symbols show vortex splits; gray symbols show vortex displacements. Dots show stratospheric warmings that are also ESEs; triangles show stratospheric warmings that are not ESEs. (a) Mean 1-10 days after the central date on the 10-hPa pressure surface, (b) mean 10-60 days after the central date on the 1000-hPa level, and (c) a scatterplot of the data in (a) and (b).

displacements (gray symbols) SSWs is not obviously different, particularly during midwinter. There is a marked seasonality in the NAM index in the stratosphere, with SSWs occurring later in the winter having a much smaller NAM index than those in midwinter. This is consistent with the reduced polar cap tempera- ture anomalies for SSWs in March shown in Fig. 2. In Fig. 12a triangles mark SSWs that are not ESEs. The two SSWs during NDJF that are not ESEs are SSW 19 in early December 1981 and SSW 30 in early January 2002. While SSW 19 has only a small temperature amplitude, SSW 30 has the third largest $10-\mathrm{hPa}$ polar cap temperature anomaly in the record. This discrepancy between the amplitude of SSWs in NAM index and polar cap temperature anomaly indicates that the NAM index might not always be the most useful measure of SSW amplitude.

Figure $12 \mathrm{~b}$ shows the mean NAM index in the troposphere 10-60 days after each SSW. As in the stratosphere, there is no clear difference between the vortex splits and displacements, and there is a large scatter in the NAM index following SSWs. This is particularly true for the SSWs that are also ESEs and have large amplitude in the stratosphere. The correlation between the NAM index at $10 \mathrm{hPa}$, averaged 1-10 days after the SSW, and the NAM index at $1000 \mathrm{hPa}$, averaged 10-60 days after the SSW, is 0.69 when all SSWs are considered, but only 0.08 when ESEs are excluded. The apparent breakdown of the relationship between stratospheric and tropospheric NAM indices is shown in Fig. $12 \mathrm{c}$, where we have plotted the NAM index at $1000 \mathrm{hPa}$ versus the NAM index at $10 \mathrm{hPa}$.

The NAM index may not be the best way of characterizing the amplitude of the impact of SSWs on the troposphere, due to the difference in structure of the response patterns of the vortex splits and displacements. To test if using the NAM index as a measure of the impact of SSWs on the troposphere biases the results in Fig. 12, a similar figure is constructed that uses area-weighted RMS geopotential height anomaly from $20^{\circ}$ to $90^{\circ} \mathrm{N}$ as the diagnostic of disturbance in the troposphere. Figure 13 shows the results of this diagnostic. While using the RMS geopotential height diagnostic reduces the scatter both in the troposphere and stratosphere, we find, again, little measurable difference in the change to the tropospheric response following vortex splitting and vortex displacements.

In summary, the results presented here lead us to conclude that while vortex splits and vortex displacements have substantially different structures in the stratosphere and different precursors, their integrated hemispheric impact on the troposphere is broadly similar. This result is contrary to that shown by Nakagawa and Yamazaki (2006), who found that wavenumber 2 SSWs propogate into the troposphere while wavenumber 1 SSWs do not. In their study SSWs are separated into those that do and do not influence the tropospheric flow, and they then show that the mean state of the wave flux prior to the SSWs has wavenumber 2 char- 
(a) Geopotential Height Anomaly $10 \mathrm{hPa} 1$ to 10 days
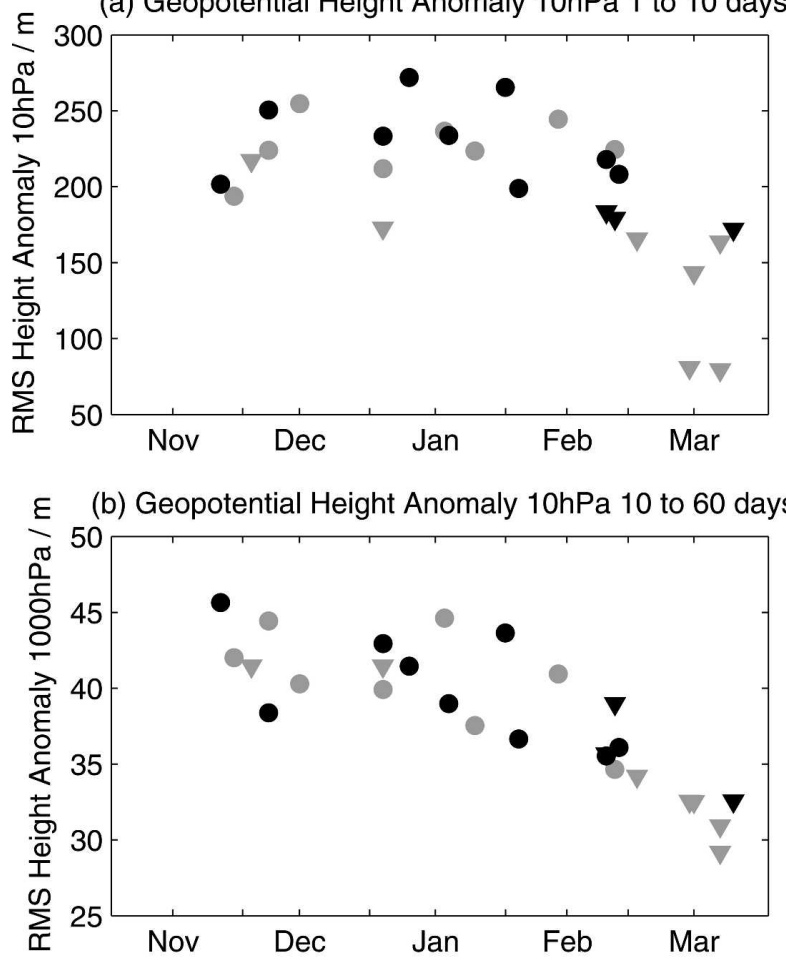

E (c) Height Anomaly $10 \mathrm{hPa}$ vs Height Anomaly $1000 \mathrm{hPa}$

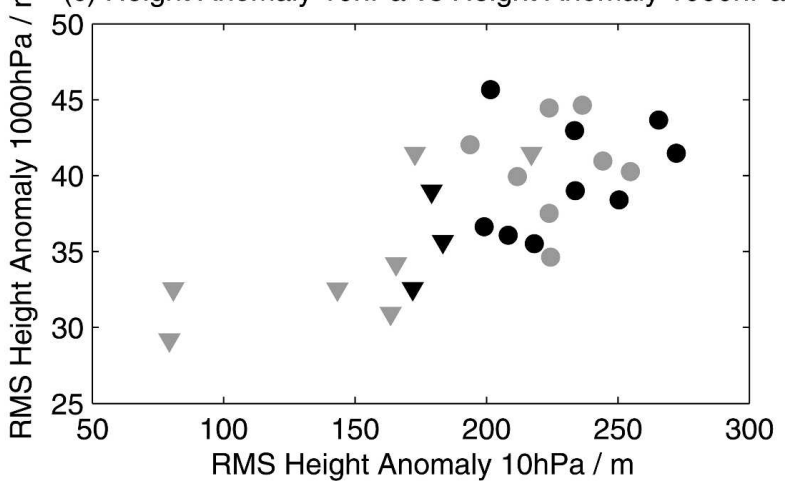

FIG. 13. Same as in Fig. 12, but for mean area-weighted RMS geopotential height anomaly at $20^{\circ}-90^{\circ} \mathrm{N}$ for each individual stratospheric warming.

acteristics. This is not the same as showing that all events that influence the troposphere have wavenumber 2 characteristics; as Nakagawa and Yamazaki also state, approximately half of their wavenumber $1 \mathrm{SSWs}$ influence the tropospheric temperature structure.

\section{Modeling benchmarks}

Beyond contributing to a better understanding of SSWs, a further motivation for constructing the climatology we have just described is to be of practical help to the many modeling teams actively working to de- velop accurate GCMs of the stratosphere. An important component of that effort is the validation of stratosphere-resolving GCM. To date, GCM validation attempts have largely focused on comparing the statistics (e.g., the time mean) of model fields with those available from the reanalyses; see Pawson et al. (2000) for a recent summary. An alternative approach, which is just now starting to be undertaken by the stratospheric modeling community, consists of focusing instead on individual processes involved in the coupled climate and chemistry of the stratosphere (Eyring et al. 2004). As we have already argued, SSWs are the most dramatic dynamical process in the stratosphere, and as such deserve the highest attention.

With this in mind we present, in Table 3, a series of dynamical benchmarks for SSWs. This table should be useful in validating numerical model simulations of SSWs. The numbers in the tables are constructed from the NCEP-NCAR reanalysis dataset. The standard error of each estimate is shown in brackets. SSWs are also divided by type, into vortex splits and vortex displacements.

The benchmarks in Table 3 were chosen to represent the life cycle of SSWs, and the ordering in the table is meant to indicate the relative importance of the diagnostics. The benchmarks are as follows:

1) The frequency of major sudden warmings per year. Stratosphere-resolving GCMs should have approximately the correct number of major stratospheric sudden warmings.

2) The area-weighted mean 10-hPa polar cap temperature anomaly, $90^{\circ}-50^{\circ} \mathrm{N}, \pm 5$ days from the central date $\left(\Delta T_{10}\right)$. SSWs should have the correct amplitude in the middle stratosphere, the level at which SSWs are defined.

3) The area-weighted mean 100-hPa polar cap temperature anomaly, $90^{\circ}-50^{\circ} \mathrm{N}, \pm 5$ days from the central date $\left(\Delta T_{100}\right.$.) SSWs should have the correct amplitude in the lower stratosphere, indicating that the coupling between the middle and lower stratosphere is adequate.

4) The difference in zonal mean zonal wind, at $60^{\circ} \mathrm{N}$ and $10 \mathrm{hPa}, 15-5$ days prior to the central date minus minus $0-5$ days after the central date $\left(\Delta U_{10}\right)$. SSWs should result in a realistic deceleration of the zonal mean zonal wind in the middle stratosphere.

5) The area-weighted, mean, 100-hPa $\overline{v^{\prime} T^{\prime}}$ anomaly, 20-0 days before the central date $\left(\Delta \overline{v^{\prime} T_{100}^{\prime}}\right)$. The SSW should be proceeded by an appropriate amount of heatflux, indicating that the cause of the warming is the upward propagation of tropospheric Rossby waves. 
TABLE 3. Dynamical benchmarks for major midwinter sudden warmings. Numbers in parentheses indicate standard error. For the definition of each benchmark, see text.

\begin{tabular}{|c|c|c|c|}
\hline Benchmark & All SSWs & Vortex displacement & Vortex splitting \\
\hline 1) Frequency (SSWs yr ${ }^{-1}$ ) & $0.60(0.10)$ & $0.33(0.07)$ & $0.27(0.07)$ \\
\hline 2) $\Delta T_{10}(\mathrm{~K})$ & $7.4(0.8)$ & $6.8(1.2)$ & $8.1(1.1)$ \\
\hline 3) $\Delta T_{100}(\mathrm{~K})$ & $2.0(0.3)$ & $1.7(0.4)$ & $2.4(0.3)$ \\
\hline 4) $\Delta U_{10}\left(\mathrm{~m} \mathrm{~s}^{-1}\right)$ & $26.2(1.8)$ & $22.5(2.0)$ & $30.9(2.5)$ \\
\hline 5) $\Delta \bar{v}^{\prime} T_{100}^{\prime}\left(\mathrm{K} \mathrm{ms}^{-1}\right)$ & $8.5(1.0)$ & $8.6(1.4)$ & $8.2(1.4)$ \\
\hline 6) $\Delta \phi_{1000}(\mathrm{~m})$ & $38.3(0.9)$ & $37.8(1.3)$ & $38.9(1.1)$ \\
\hline 7) $\Delta$ NAMI $_{1000}$ & $-0.7(0.2)$ & $-0.6(0.2)$ & $-0.8(0.3)$ \\
\hline
\end{tabular}

6) The RMS, area-weighted, 1000-hPa geopotential height anomaly, $20^{\circ}-90^{\circ} \mathrm{N}, 10-60$ days after the central date $\left(\Delta \phi_{1000}\right)$. Following each SSW, the seasonal evolution of the troposphere should be disturbed, indicating the correct level of stratosphere-troposphere coupling.

7) The mean, 100- hPa NAM index, 10-60 days after the central date $\left(\triangle N A M I_{1000}\right)$. The tropospheric response following each warming SSW should project onto the NAM pattern with the proper amplitude. Although we note in the previous section that the NAM might not be a discriminating diagnostic of the impact of SSWs on the troposphere, we nevertheless include it here because of its widespread use.

\section{Conclusions}

In this paper, we have constructed a new climatology of major midwinter stratospheric sudden warming events, based on a new algorithm that we have developed to automatically extract SSWs from large datasets and distinguish between different types of SSWs. This new algorithm compares favorably with a subjective analysis of the data and is relatively easy to implement. With this tool, we are able to provide the following answers, to the questions posed in the introduction:

1) SSWs occur with a mean frequency of 0.62 events per winter season. Vortex splits are almost as frequent as vortex displacements; $46 \%$ of SSWs between 1957/58 and 2001/02 were vortex splits. The mean amplitude of SSWs in the middle stratosphere is $7.8 \mathrm{~K}$, and there is little difference in the mean amplitude of vortex displacements and vortex splits.

2) The seasonal distribution of vortex splits and vortex displacements is very different. Vortex splits occur mostly during January and February and only occasionally during March, while vortex displacements occur during all winter months, but are most common in December and March. There is no discernible trend in the number of SSWs between the 1960s and early 2000s, although there is large variability in the number of SSWs throughout that period, the early 1970s and late 1990s being particularly dynamically active.

3) Vortex displacements and splits should be considered dynamically distinct. Prior to vortex displacements and vortex splits, the vertical and horizontal structure of the stratosphere and troposphere is different. In particular, anomalously strong zonal flow in the troposphere appears essential for the occurrence of vortex splits. Vortex splits are accompanied by a significantly anomalous flow in the Pacific sector. There is also clear evidence of early, precursor wave activity for the vortex splits but not for vortex displacements.

4) While there are some differences in the spatial structures of the tropospheric impact of vortex displacements and vortex splits, there is little difference in the averaged tropospheric impact. This suggests that the mechanism for the impact of the stratosphere on the tropospheric flow following major stratospheric disturbances might have little dependence upon the precise structure of anomalies in the lower stratosphere.

With these results in mind, we proceed, in the second paper, to an analysis of SSWs in a number of current, stratosphere-resolving GCMs.

Acknowledgments. We are grateful to Alan O'Neill, Lesley Gray, Paul Kushner, Marvin Geller, Darryn Waugh, Bill Randel, and Gavin Esler for useful suggestions, and particularly to Matthew Wittman for substantial contributions to the discussion, ideas, and techniques developed in this study. The NCEP-NCAR reanalyses were obtained from the IRI Ingrid data server at the Lamont-Doherty Earth Observatory of Columbia University. The ERA-40 data were obtained from the ECMWF data server. This research was funded, in part, by an award to the Cooperative Institute for Climate Applications and Research (CICAR) from the U.S. National Oceanic and Atmospheric Administra- 
tion and, in part, from a grant to Columbia University from the U.S. National Science Foundation.

\section{REFERENCES}

Adams, J. C., and P. N. Swarztrauber, 1999: SPHEREPACK 3.0: A model development facility. Mon. Wea. Rev., 127, 18721878.

Andrews, D. G., J. R. Holton, and C. B. Leovy, 1985: Middle Atmosphere Dynamics. Academic Press, 489 pp.

Baldwin, M. P., and J. R. Holton, 1988: Climatology of the stratospheric polar vortex and planetary wave breaking. J. Atmos. Sci., 45, 1123-1142.

_ , and T. J. Dunkerton, 1989: The stratospheric major warming of early December 1987. J. Atmos. Sci., 46, 2863-2884.

— related tropospheric circulation anomalies. J. Climate, 8, 649667.

—_, and T. J. Dunkerton, 2001: Stratospheric harbingers of anomalous Weather Regimes. Science, 294, 581-584.

Castleman, K. R., 1996: Digital Image Processing. Prentice Hall, $667 \mathrm{pp}$.

Charlton, A. J., A. O’Neill, A. C. Massacand, and W. A. Lahoz, 2004: Sensitivity of tropospheric forecasts to stratospheric initial conditions. Quart. J. Roy. Meteor. Soc., 130, 1771-1792.

Eyring, V., and Coauthors, 2004: Comprehensive summary on the Workshop on Process-Oriented Validation of Couple Chemistry-Climate Models. SPARC Newsletter, No. 23, SPARC Office, Toronto, ON, Canada, 5-11.

Finger, F. G., and S. Teweles, 1964: The mid-winter 1963 stratospheric warming and circulation change. J. Appl. Meteor., 3, $1-15$.

Fusco, A. C., and M. L. Salby, 1999: Interannual variations of total ozone and their relationship to variations in planetary wave activity. J. Climate, 12, 1619-1629.

Gillett, N., and D. W. J. Thompson, 2003: Simulation of recent Southern Hemisphere climate change. Science, 302, 273-275.

Hare, F. K., 1960: The disturbed circulation of the arctic stratosphere. J. Meteor., 17, 36-51.

$\mathrm{Hu}, \mathrm{Y}$. Y., and K. K. Tung, 2002: Interannual and decadal variations of planetary wave activity, stratospheric cooling, and the Northern Hemisphere Annular Mode. J. Climate, 15, 1659-1673.

Jacobi, C., D. Kurschner, H. G. Muller, D. Pancheva, N. J. Mitchell, and B. Naujokat, 2003: Response of the mesopause region dynamics to the February 2001 stratospheric warming. J. Atmos. Terr. Phys., 65, 843-855.

Johnson, K. W., A. J. Miller, and M. E. Gelman, 1969: Proposed indices characterizing stratospheric circulation and temperature fields. Mon. Wea. Rev., 97, 565-570.

Kallberg, P., A. Simmons, S. Uppala, and M. Fuentes, 2004: The ERA-40 archive. ERA-40 Project Report Series, No. 17, ECMWF, $31 \mathrm{pp}$

Kistler, R., and Coauthors, 2001: The NCEP-NCAR 50-Year Reanalysis: Monthly means CD-ROM and documentation. Bull. Amer. Meteor. Soc., 82, 247-267.

Kruger, K., B. Naujokat, and K. Labitzke, 2005: The unusual midwinter warming in the Southern Hemisphere stratosphere 2002: A comparison to Northern Hemisphere phenomena. $J$. Atmos. Sci., 62, 603-613.

Labitzke, K., 1977: Interannual variability of the winter stratosphere in the Northern Hemisphere. Mon. Wea. Rev., 105, $762-770$.
, 1981: Stratospheric-mesospheric disturbances: A summary of observed characteristics. J. Geophys. Res., 86, 9665-9678.

_ and B. Naujokat, 2000: The Lower Arctic Stratosphere since 1952. SPARC Newsletter, No. 15, SPARC Office, Toronto, ON, Canada.

Limpasuvan, V., D. W. J. Thompson, and D. L. Hartmann, 2004: The life cycle of the Northern Hemisphere sudden stratospheric warmings. J. Climate, 17, 2584-2596.

Manney, G. L., W. A. Lahoz, R. Swinbank, A. O'Neill, P. M. Connew, and R. W. Zurek, 1999: Simulation of the December 1998 stratospheric major warming. Geophys. Res. Lett., 26, 2733-2736.

— K. Kruger, J. L. Sabutis, S. A. Sena, and S. Pawson, 2005: The remarkable 2003-2004 winter and other recent warm winters in the Arctic stratosphere since the late 1990s. J. Geophys. Res., 110, D04107, doi:10.1029/2004JD005367.

Matsuno, T., 1971: A dynamical model of stratospheric warmings. J. Atmos. Sci., 28, 1479-1494.

McIntyre, M. E., 1982: How well do we understand the dynamics of stratospheric warmings? J. Meteor. Soc. Japan, 60, 37-65.

Nakagawa, K. I., and K. Yamazaki, 2006: What kind of stratospheric sudden warming propagates to the troposphere? Geophys. Res. Lett., 33, L04801, doi:10.1029/2005GL024784.

Nash, E. R., P. A. Newman, J. E. Rosenfield, and M. R. Scoeberl, 1996: An objective determination of the polar vortex edge using Ertels potential vorticity. J. Geophys. Res., 101, 94719478.

Naujokat, B., and K. Labitzke, 1993: Collection of reports on the stratospheric circulation during the winters 1974/75-1991/2. Scientific Commission on Solar Terrestrial Physics, Rep. 1, $301 \mathrm{pp}$.

_, K. Kruger, K. Matthes, J. Hoffman, M. Kunze, and K. Labitzke, 2002: The early major warming in December 2001Exceptional? Geophys. Res. Lett., 29, 2023, doi:10.1029/ 2002GL015316.

Newman, P. A., and J. E. Rosenfield, 1997: Stratospheric thermal damping times. Geophys. Res. Lett., 24, 433-436.

- E. R. Nash, and E. R. Rosenfield, 2001: What controls the temperature of the Arctic stratosphere during the spring? $J$. Geophys. Res., 106, 19 999-20 010.

Norton, W. A., 2003: Sensitivity of Northern Hemisphere surface climate to simulation of the stratospheric polar vortex. Geophys. Res. Lett., 30, 1627, doi:10.1029/2003GL016958.

O'Neill, A., 2003: Stratospheric sudden warmings. Encyclopedia of Atmospheric Sciences, J. R. Holton, J. A. Pyle, and J. A. Curry, Eds., Elsevier, 1342-1353.

_ , and C. E. Youngblut, 1982: Stratospheric warmings diagnosed using the transformed Eulerian-mean equations and the effect of the mean state on wave propagation. J. Atmos. Sci., 39, 1370-1386.

Palmer, T. N., 1981: Diagnostic study of a wavenumber-2 stratospheric sudden warming in a transformed Eulerian mean formalism. J. Atmos. Sci., 38, 844-855.

Pawson, S., and B. Naukojat, 1999: The cold winters of the middle 1990s in the Northern Lower Stratosphere. J. Geophys. Res., 104, 14 209-14 222.

_ , and Coauthors, 2000: The GCM-Reality Intercomparison Project for SPARC: Scientific issues and initial results. Bull. Amer. Meteor. Soc., 81, 781-796.

Polvani, L. M., and P. J. Kushner, 2002: Tropospheric response to stratospheric perturbations in a relatively simple general circulation model. Geophys. Res. Lett., 29, 1114, doi:10.1029/ $2001 \mathrm{GL} 014284$. 
— cursor to extreme stratospheric events and subsequent weather regimes. J. Climate, 17, 3548-3554.

Quiroz, R. S., 1969: The warming of the stratosphere in February 1966 and the associated structure of the mesosphere. Mon. Wea. Rev., 97, 541-552.

_ 1975: The stratospheric evolution of sudden warmings in 1969-74 determined from measured infrared radiation fields. J. Atmos. Sci., 32, 213-224.

Randel, W. J., and B. A. Boville, 1987: Observations of a major stratospheric warming during December 1964. J. Atmos. Sci., 44, 2179-2186.

Sassi, F., D. Kinnison, B. A. Boville, R. R. Garcia, and R. R. Oble, 2004: Effect of El Niño-Southern Oscillation on the dynamical, thermal, and chemical structure of the middle atmosphere. J. Geophys. Res., 109, D17108, doi:10.1029/ 2003JD004434.

Scherhag, R., 1952: Die explosionsartigen Stratosphärenerwärmungen des Spätwinters 1951-52. Ber. Dtsch. Wetterdienst (US Zone), 6, 51-63.

Scott, R. K., D. G. Dritschel, L. M. Polvani, and D. W. Waugh, 2004: Enhancement of Rossby wave breaking by steep potential vorticity gradients in the winter stratosphere. J. Atmos. Sci., 61, 904-918.

Sexton, D. M. H., 2001: The effect of stratospheric ozone depletion on the phase of the Antarctic Oscillation. Geophys. Res. Lett., 28, 3697-3700.

Shindell, D. T., R. L. Miller, G. Schmidt, and L. Pandolfo, 1999: Simulation of recent northern winter climate trends by greenhouse-gas forcing. Nature, 399, 452-455.

Taguchi, M., and D. L. Hartmann, 2006: Increased occurrence of stratospheric sudden warmings during El Niño as simulated by WACCM. J. Climate, 19, 324-332.

Teweles, S., and F. G. Finger, 1958: An abrupt change in stratospheric circulation beginning in mid-January 1958. Mon. Wea. Rev., 86, 23-28.

Thompson, D. W. J., and S. Solomon, 2002: Interpretation of recent Southern Hemisphere climate change. Science, 296, 895-899.

_ M. P. Baldwin, and J. M. Wallace, 2002: Stratospheric connection to Northern Hemisphere wintertime weather: Implications for predictions. J. Climate, 15, 1421-1428.

Vallis, G. K., E. P. Gerber, P. J. Kushner, and B. A. Cash, 2004: A mechanism and simple dynamical model of the North Atlantic Oscillation and annular modes. J. Atmos. Sci., 61, 264-280.

Wallace, J. M., and D. S. Gutzler, 1981: Teleconnections in the geopotential height field during the Northern Hemisphere winter. Mon. Wea. Rev., 109, 784-812.

Waugh, D. W., 1997: Elliptical diagnostics of stratospheric polar vortices. Quart. J. Roy. Meteor. Soc., 123, 1725-1748.

— elliptical diagnostics. J. Atmos. Sci., 56, 1594-1613.

Wilks, D. S., 1995: Statistical Methods in the Atmospheric Sciences. Academic Press, 648 pp.

Wittman, M. A. H., L. M. Polvani, R. K. Scott, and A. J. Charlton, 2004: Stratospheric influence on baroclinic lifecycles and its connection to the Arctic Oscillation. Geophys. Res. Lett., 31, L16113, doi:10.1029/2004GL020503.

_ A. J. Charlton, and L. M. Polvani, 2007: The effect of lower stratospheric shear on baroclinic instability. J. Atmos. Sci., 64, 479-496. 